\title{
Aportes al conocimiento del plutonismo del Arco Mocoa- Santa Marta durante el Jurásico Temprano-Medio, en la margen noroccidental de los Andes, Colombia
}

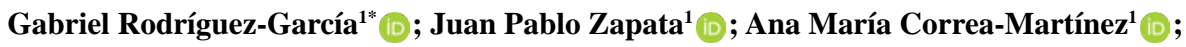 \\ Diego Armando Ramírez ${ }^{1}$ (D) ; Gloria Obando ${ }^{1}$ (1)
}

Forma de citar: Rodríguez-García, G.; Zapata, J.P.; Correa-Martínez, A.M.; Ramírez, D.A.; Obando, G. (2020). Aportes al conocimiento del plutonismo del Arco Mocoa-Santa Marta durante el Jurásico Temprano-Medio, en la margen noroccidental de los Andes, Colombia. Boletín de Geología, 42(3), 15-50. https://doi.org/10.18273/revbol.v42n3-2020001

Material suplementario: Este artículo contiene Material suplementario (Tablas TS1, TS2, TS3, TS4, TS5, TS6 y TS7).

\begin{abstract}
Resumen
A partir de la integración de información de campo, con datos petrográficos, geoquímicos de roca total, isotópicos y geocronológicos, se realizó la comparación de los diferentes segmentos que conforman el Arco Mocoa-Santa Marta (AMSM). Este arco, que aflora en el Valle Superior del Magdalena, la Serranía de San Lucas, la Sierra Nevada de Santa Marta y la Alta Guajira, se emplazó en un basamento Neo-proterozoico y en granitoides de un arco Pérmico, los cuales fueron posteriormente dispersados a lo largo de la Paleomargen Suramericana. El plutonismo del AMSM se caracteriza por la migración composicional en sentido W-E, con la formación de intrusivos de cuarzomonzonita, monzonita, charnoquita, tonalita y granodiorita hacia el occidente y la formación de plutones de monzogranito y sienogranito hacia el oriente; también existe un enriquecimiento en $\mathrm{SiO}_{2}$ en sentido S-N. Los plutones del AMSM cristalizaron entre el Jurásico Temprano ( 193 Ma) y el Jurásico Medio ( $\sim 164 \mathrm{Ma})$, y fueron generados por al menos cuatro eventos de cristalización. Los plutones que conforman este arco son de Tipo I, calcoalcalinos con leve variación hacia los granitoides alcalino cálcicos. Los plutones más antiguos y occidentales son mayoritariamente metaluminosos y los más jóvenes y orientales son peraluminosos, todos ellos formados dentro del mismo contexto de evolución magmática de un arco de margen continental erosiva con vulcanismo asociado. La temperatura de cristalización del circón $\mathrm{T}_{\text {zircti }}$ para el conjunto de plutones del Cinturón Occidental presenta un pico de cristalización a $860^{\circ} \mathrm{C}$, mientras que los plutones del Cinturón Oriental presentan picos de cristalización a $714^{\circ} \mathrm{C}, 807^{\circ} \mathrm{C}$ y $854^{\circ} \mathrm{C}$, con una alta dispersión.
\end{abstract}

Palabras clave: Magmatismo Jurásico; Dataciones U-Pb; Colombia; Terreno Chibcha.

\section{Contributions to the knowledge of plutonism of the Mocoa-Santa Marta Arc during the Early - Middle Jurassic, on the northwestern margin of the Andes, Colombia}

\begin{abstract}
Based on the integration of field information with petrographic, whole rock geochemical, isotopic and geochronological data, a comparison of the different tectonic blocks that make up the Mocoa-Santa Marta Arc (AMSM) was made. This arc, which crops out in the Upper Magdalena Valley, La Serranía de San Lucas, La Sierra Nevada de Santa Marta and La Alta Guajira, was emplaced in a Neo-proterozoic basement and in granitoids of a Permian arc, which were later dispersed along the South American Paleomargin. The plutonism of the AMSM is characterized by a compositional migration in the W-E direction, with the formation of intrusive quartz monzonite, monzonite, charnockite, tonalites and granodiorites intrusions to the west and the formation of monzogranite and syenogranite plutons towards the east; there is also an enrichment in $\mathrm{SiO}_{2}$ in the S-N direction. AMSM plutons crystallized between the Early Jurassic ( $\sim 193 \mathrm{Ma})$ and middle Jurassic ( 164 Ma), and were generated by at least four crystallization events. The plutons that make up this arc are I-type, calc-alkaline, with slight variation toward calcium alkaline granitoids. The oldest and western plutons are mostly metaluminous and the youngest and eastern plutons are peraluminous, all formed within the same context of magmatic evolution of an erosive continental margin arc with associated vulcanism. The zircon crystallization temperature $\left(\mathrm{T}_{\text {zirc } \mathrm{ij}}\right)$ for all western plutons has a crystallization peak at $860^{\circ} \mathrm{C}$, while the eastern belt plutons have $\mathrm{T}_{\text {zircTi }}$ crystallization peaks at $714^{\circ} \mathrm{C}, 807^{\circ} \mathrm{C}$ and $854^{\circ} \mathrm{C}$, with a high dispersion.
\end{abstract}

Keywords: Jurassic Magmatism; U-Pb dating; Colombia; Chibcha Terrain.

${ }^{1}$ Grupo de Estudios Geológicos Especiales, Servicio Geológico Colombiano, Medellín, Colombia. (*) grodriguez@sgc.gov.co; jpzapata@sgc.gov.co; amcorrea@sgc.gov.co; dramirezs@sgc.gov.co; gobando@sgc.gov.co 


\section{Introducción}

El plutonismo Jurásico en el norte de los Andes representa el evento magmático de mayor extensión que ocurrió a lo largo de la paleomargen de Suramerica. Rodríguez et al. (2020) plantean la existencia en esta paleomargen de tres arcos para el norte de los Andes de Suramerica: el primero de ellos representado por granitos peraluminosos, con importante fusión cortical, emplazados en el orógeno Famatiniano del Macizo de Santander. La cristalización de este arco duró $\sim 30$ $\mathrm{Ma}$, entre ca. 214 y $184 \mathrm{Ma}$. El segundo arco, objeto del presente estudio lo llamamos Arco Mocoa-Santa Marta (AMSM), se desarrolló a lo largo de la margen noroccidental de Suramérica, presenta migración composicional y variaciones en edad en sentido oeste-este (Rodríguez et al., 2018, 2020), inició con rocas metaluminosas y con el tiempo evolucionó para formar rocas peraluminosas graníticas, está emplazado en basamento Neo-proterozoico, y fue dispersado en segmentos que hoy se encuentran en el Valle Superior del Magdalena (VSM), la Serranía de San Lucas (SSL), la Sierra Nevada de Santa Marta (SNSM) y la Alta Guajira (AG). La cristalización de los plutones de este arco duró 30 Ma, entre ca. 193 y $164 \mathrm{Ma}$. El tercer arco comprende los batolitos de Ibagué y Segovia, metaluminosos de composición tonalítica, con dos episodios de cristalización magmática entre 152 y 158 Ma y entre 136 Ma y 145 Ma, con una duración del arco de $\sim 20 \mathrm{Ma}$, el cual ocurrió durante y posterior a la colisión del Terreno Tahamí contra el Terreno Chibcha en el Jurásico Superior.

En este trabajo se integra la información de los plutones y los segmentos dispersados que conforman el AMSM, se mejora el conocimiento sobre la edad y la evolución del plutonismo durante el Jurásico Temprano a Medio, se discuten las variaciones composicionales (petrográfica y química) en sentido norte-sur y esteoeste al interior del arco; se correlacionan los cambios composicionales con la edad U-Pb LA-ICP-MS en circón de los pulsos magmáticos; se precisan los límites del basamento Neo-proterozoico (Terreno Chibcha - margen occidental de Gondwana) dentro del cual están emplazados los plutones; se mejora el modelo del magmatismo y se discuten las diferencias con modelos previos propuestos por investigadores como: Jaramillo y Escovar (1980), McCourt et al. (1984), Toussaint (1995), Meschede y Frisch (1998), Bayona et al. (2006, 2010), Bustamante et al. (2010, 2016), Leal-Mejía (2011), Van der Lelij et al. (2016), Spikings et al. (2015), Rodríguez et al. (2015a, 2018, 2020), Villagómez et al. (2015), Zapata et al. (2016),
Zuluaga et al. (2017), Zuluaga y López (2019) y LealMejía et al. (2019).

Este trabajo es el resultado de la integración de los datos del proyecto "Magmatismo Jurásico de Colombia" desarrollado en diferentes segmentos que componen los arcos y que se encuentran en informes de libre acceso al público generados en los últimos años, los integramos a datos ya publicados de petrografía, geoquímica, isótopos y geocronología U-Pb LA-ICPMS en circón, con el fin de mejorar el conocimiento del plutonismo del mayor de los arcos Jurásicos del norte de los Andes, el cual denominamos Arco Jurásico Mocoa-Santa Marta (AMSM), y ha sido separado del magmatismo Triásico-Jurásico de Santander (MTJS) y del Arco Jurásico-Cretácico de Ibagué-Segovia (AIS) (Rodríguez et al., 2020).

\section{Marco geológico}

La configuración actual de los Andes en Colombia es el resultado de la interacción de placas y microplacas continentales y oceánicas, con la formación y amalgamación de terrenos de diversa afinidad y el desarrollo de orógenos desde el Meso-proterozoico hasta el Cretácico Superior; además de la formación de arcos continentales y oceánicos que se emplazaron en estos terrenos y que hoy se presentan apilados a lo largo de los Andes Noroccidentales y algunos de ellos dispersados por la tectónica transcurrente de la margen Suramericana.

La configuración geológica del norte de la margen Suramericana hasta el Jurásico Superior estaba conformada al este por el Escudo de Guyana (mitad norte del cratón amazónico), con edades entre 2,51,5 Ga (Priem et al., 1982; Restrepo-Pace y Cediel, 2019) (Figura 1). La parte más occidental del escudo, está constituida por granitoides y rocas metamórficas de alto grado, que hacen parte del cinturón de Río Negro (1,84-1,72 Ga) (Tassinari, 1981; Tassinari y Macambira, 1999; Kroonenberg, 2019), el cual está intruido por granitoides anorogénicos de 1,55 Ga (e.g. Granito rapakivi de Parguaza) y cubierto localmente por areniscas y meta-areniscas de Naquén, Pedrera y Tunuí (Kroonenberg, 2019).

Al oeste del Sistema de Fallas del Borde Llanero (límite del dominio cratónico de la margen de los Andes del Norte), se levanta la margen Andina, conformada por un basamento de rocas metamórficas de alto grado (facies granulita a anfibolita alta), probablemente formadas durante la colisión continental de Amazonia y Laurentia 
durante la Orogenia Grenvilliana (Kroonenberg, 1982; Cordani et al., 2010; Ibáñez-Mejía et al., 2011; Kroonenberg, 2019) y representada por bloques conformados por las unidades Grupo Garzón, Neises de Mancagua y Guapotón, Migmatitas de Las Minas, Granito de El Recreo, Neis de San Lucas, Granulita de Los Mangos, Neis de Buritaca y Neis de Jojoncito (Kroonenberg y Diederix, 1982; Rodríguez, 1995a, 1995b; Velandia et al., 1996, 2001a, 2001b; Rodríguez et al., 2003; Jiménez-Mejía et al., 2006; Ibáñez-Mejía et al., 2011, 2015; Cuadros, 2012; Cuadros et al., 2014;
Tschanz et al., 1969a, 1974; Ordóñez-Carmona et al., 2002; Piraquive, 2017), con edades entre 1,2 a $0,85 \mathrm{Ga}$ (Ibáñez-Mejía et al., 2011, 2015).

Estos segmentos se encuentran dispersados a lo largo de la paleomargen y han sido denominados en estudios anteriores como el Terreno Chibcha (Restrepo y Toussaint, 1989; Restrepo et al., 2009) y recientemente como el Orógeno Putumayo (Ibáñez-Mejía et al., 2011, 2015) (Figura 1).

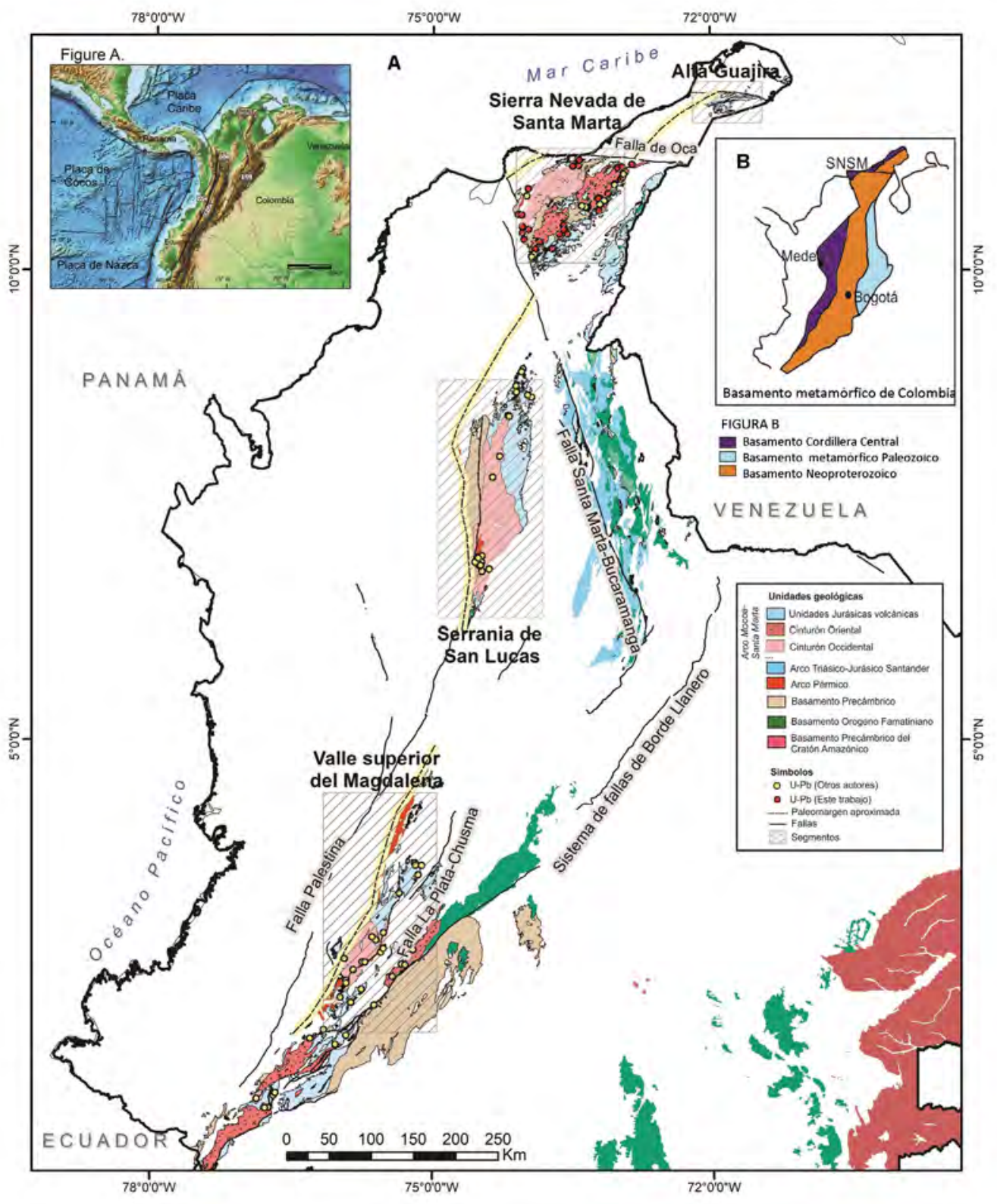

Figura 1. Segmentos del Arco Jurásico Mocoa-Santa Marta (AMSM) dispersados a lo largo de la Paleomargen. De norte a sur los segmentos Alta Guajira (AG), Sierra Nevada de Santa Marta (SNSM), Serranía de San Lucas (SSL) y Valle Superior del Magdalena (VSM). 
Al oriente del Orógeno Putumayo, en el Macizo de Santander y los Andes de Mérida, se presenta un bloque dispersado del Orógeno Caperoniense o Famatiniano de edad Paleozoico Inferior (Ordovícico) (Restrepo, 1995; Mantilla-Figueroa et al., 2016) (Figura 1); que se extiende como fragmentos desde Chile hasta Venezuela, en la protomargen occidental de Gondwana (Ramos, 2008; Otamendi et al., 2017). Este orógeno está representado en Colombia, en los macizos de Santander y Quetame, por unidades sedimentarias, metasedimentarias de muy bajo grado, esquistos, neises migmatíticos, paraneises y granitoides de arco sin-tectónicos y pos-tectónicos (Van der Lelij et al., 2016; Mantilla-Figueroa et al., 2016; TazzoRangel et al., 2019), presentando algunas unidades metamorfismo de la facies anfibolita alta y granulita en la cúspide de la orogenia famatiniana ( 470 Ma) (Zuluaga et al., 2017; Tazzo-Rangel et al., 2019). Sobre este bloque, se desarrolló a finales del Tríásico y principios del Jurásico ( 214 -184 Ma) (Van der Lelij et al., 2016; Rodríguez et al., 2020), un magmatismo que formó cuerpos batolíticos y stocks de composición predominante monzogranítica a sienogranítica (Ward et al., 1973; Rodríguez et al., 2020), peraluminosos de Tipo I (Rodríguez et al., 2020; Zuluaga y López, 2019), no correlacionables con los plutones Jurásicos que intruyeron el basamento Neo-proterozoico (Rodríguez et al., 2020) (Figura 1).

El basamento Neo-proterozoico, en la Margen Andina, fue cubierto por secuencias sedimentarias marinas e, intruido por plutones formados por la subducción de la placa oceánica del paleo-Pacífico durante el Carbonífero (Leal-Mejía, 2011; Rodríguez et al., 2019a), y el Pérmico (Rodríguez et al., 2019a) (Figura 1). Posterior al magmatismo Pérmico, secuencias locales continentales y marinas (formaciones Luisa, Payandé y Los Indios) se depositaron durante el Triásico sobre el basamento metamórfico y los plutones Pérmicos, seguido por el desarrollo de un nuevo arco en la margen continental durante el Jurásico Temprano y Medio, que duró activo 30 Ma (197-167 Ma) (Rodríguez et al., 2018, 2020) (Figura 1).

El colapso del arco Jurásico ocurrió durante el Jurásico Superior con la colisión del Terreno Tahamí contra la margen occidental de Gondwana (Blanco-Quintero et al., 2014; Rodríguez et al., 2017b; Rodríguez et al., 2020), formando un nuevo orógeno de edad Jurásico Superior constituido por anfibolitas, neises, esquistos verdes y negros, y cuarcitas, del cual hacen parte el
Complejo Cajamarca, los Neises y Anfibolitas de Tierradentro y el Complejo La Cocha-Río Téllez (Blanco-Quintero et al., 2014; Zapata-García et al., 2017; Rodríguez et al., 2017b, 2018, 2019a, 2020). El nuevo orógeno Jurásico fue amalgamado a la margen occidental de Suramérica contra el orogéno Putumayo (Terreno Chibcha) y contra el arco Jurásico TempranoMedio.

El arco Jurásico Temprano-Medio fue posteriormente dispersado junto con el basamento Neo-proterozoico, y se encuentra dentro de segmentos separados en el Valle Superior del Magdalena (VSM), la Serranía de San Lucas (SSL), la Sierra Nevada de Santa Marta (SNSM) y la Alta Guajira (AG) (Bayona et al., 2010; Villagómez et al., 2015) (Figuras 1 y 2), y está conformado por dos cinturones de plutones y por unidades volcánicas (Tschanz et al., 1969a, 1974; Cediel et al., 1981; Maze y Hargraves, 1984; Clavijo, 1995; González et al., 2015a; Rodríguez et al., 2015f; 2018, 2020).

\section{Metodología}

Para el estudio del magmatismo Jurásico, el Servicio Geológico Colombiano (SGC) desarrolló el proyecto Magmatismo Jurásico de Colombia entre el 2015 y el 2019. En este proyecto se hizo la recopilación de información de proyectos anteriores de cartografía regional y artículos publicados. Se realizó trabajo de campo, muestreo de rocas para petrografía, geoquímica y geocronología en el VSM, la Cordillera Central (CC), la SNSM y la AG. La información de la SSL se compiló de González et al. (2015a, 2015b, 2015c, 2015d).

\section{Petrografía}

Se realizó el análisis petrográfico de 68 secciones delgadas y se integró la información de todos los segmentos para un total de 480 análisis petrográficos. Se utilizaron microscopios petrográficos Leitz y Olympus bajo luz polarizada para las cuales se hicieron conteos mineralógicos de 300 puntos por muestra. Las rocas se clasificaron siguiendo los diagramas propuestos por Streckeisen $(1976,1978)$ y Le Maitre et al. (2002). Se recopilaron los análisis petrográficos realizados por Zuluaga et al. (2009) para la AG; González et al. (2015a, 2015b, 2015c) para la SSL y Rodríguez et al. (2015f) para el VSM. 


\section{Litogeoquímica}

Se realizaron análisis geoquímicos de roca total en el laboratorio del SGC en Bogotá a 48 rocas de la SNSM y se compilaron 145 análisis adicionales del VSM, SSL, SNSM y AG (Zuluaga et al., 2009; González et al., 2015a, 2015b, 2015c; Quandt et al., 2018; Rodríguez et al., 2018). Los óxidos mayores se determinaron aplicando fluorescencia de rayos $\mathrm{X}$ en un espectrómetro AXIOS Mineral analítico, que incluye elementos traza como V, Mo, Nb, Ta, W, Zr y Hf. Se utilizaron como estándares MRC-GSR-2 y MRCBHVO-2. Los óxidos mayores se cuantificaron a partir de muestras fundidas con metaborato y tetraborato de litio, mientras que los elementos trazas a partir de muestras prensadas. Para el análisis de elementos traza, se usó un espectrómetro de masas con plasma inductivamente acoplado, ICP-MS, Perkin Elmer NEXION. Las muestras se disolvieron gradualmente en ácidos inorgánicos fuertes ( $\mathrm{HF}, \mathrm{HNO}_{3}, \mathrm{HClO}_{4} \mathrm{y}$ $\mathrm{HCl}$ ). El proceso se realizó en un sistema abierto utilizando varias rampas de temperatura y tiempos de calentamiento. Para interpretar los óxidos principales, los valores se recalcularon considerando la pérdida en la ignición (LOI). Los diagramas petrográficos y geoquímicos se obtuvieron usando el software GCDkit de Janoušek et al. (2006).

\section{Geocronología U-Pb en circón}

Las dataciones $\mathrm{U}-\mathrm{Pb}$ en circón se realizaron en el Laboratorio de Ablación Láser del SGC y en el Laboratorio de Estudios Isotópicos del Centro de Geociencias de la Universidad Nacional Autónoma de México (UNAM). Las tablas de resultados se presentan en la Tabla TS7 y la interpretación de cada edad puede ser consultada en Rodríguez et al. (2019b).

Los análisis isotópicos se realizaron en el Laboratorio de Ablación Láser del SGC, utilizando un espectrómetro de masas de plasma de acoplamiento inductivo ELEMENT $2^{\mathrm{TM}}$, acoplado a un sistema de ablación láser Photon Machines con un láser de excitación de $193 \mathrm{~nm}$. Los tiempos de integración de 0-32 s se utilizaron para la línea de base, mientras que los tiempos de integración de 32,5 - 7 s se utilizaron para las muestras y los estándares de referencia. Los puntos de ablación fueron de $30 \mu \mathrm{m}$ de diámetro, como estándares de referencia se utilizó Plešovice $(337,13$ \pm 0,37 Ma; Sláma et al., 2008), 91500 (1065 Ma; Wiedenbeck et al., 1995) y Dromedary (Schoene et al., 2015). La reducción de los datos se realizó utilizando el software Iolite IGORPro (Paton et al., 2011), y los resultados se corrigieron para obtener una pista común según el modelo de Stacey y Kramers (1975). La discordancia se evaluó en función del diferencial entre las edades de ${ }^{206} \mathrm{~Pb} /{ }^{238} \mathrm{U}$ y ${ }^{207} \mathrm{~Pb} /{ }^{235} \mathrm{U}$. Las edades de la muestra se calcularon utilizando los valores medios ponderados de las edades ${ }^{206} \mathrm{~Pb} /{ }^{238} \mathrm{U}$ para cristales $<800$ Ma y las edades ${ }^{207} \mathrm{~Pb} /{ }^{206} \mathrm{~Pb}$ para cristales $>800 \mathrm{Ma}$. Los resultados finales se presentan discriminando a dos desviaciones estándar y los cálculos de las edades y los gráficos geocronológicos se hicieron con el programa Isoplot V4.15 (Ludwig, 2012).

En el Laboratorio de Estudios Isotópicos (LEI) en el Centro de Geociencias de la Universidad Nacional Autónoma de México (UNAM), campus Juriquilla, se dataron siete muestras de la SNSM, empleando un Thermo $X$ series QICPMS acoplado a un Resonetics, estación de trabajo láser excimer Resolución M050. Los procedimientos y equipos se describen en detalle en Solari et al. (2010). Los puntos analizados fueron de 23 micrómetros. Las incertidumbres de $2 \sigma$ propagadas se lograron según Paton et al. (2010). Las proporciones ${ }^{207} \mathrm{~Pb} /{ }^{206} \mathrm{~Pb}$, edades y errores se calcularon según Petrus y Kamber (2012). Las concentraciones de U y Th fueron calculadas empleando un circón estándar externo de acuerdo a Paton et al. (2010). Junto con las edades $\mathrm{U}-\mathrm{Pb}$ se obtuvieron los elementos trazas de los circones. La interpretación de las edades de la SNSM se encuentra en el trabajo de Rodríguez et al. (2019b).

\section{Resultados}

La integración e interpretación de datos de petrografía, geoquímica de roca total, geocronología $\mathrm{U}-\mathrm{Pb}$, geoquímica de circón y geoquímica isotópica (datos compilados de Leal-Mejía et al., 2019; Ríos-Blandón., 2016; Quandt et al., 2018), se realiza para todo el conjunto de plutones que conforman el AMSM, integrando la información de los plutones que afloran en el VSM, SSL, SNSM y AG (Figura 2).

Basados en la división de los cinturones de plutones propuesta por Tschanz et al. (1969a, 1969b) y Rodríguez et al. (2019b) para la SNSM; Jaramillo y Escovar (1980), Núñez et al. (1996) y Rodríguez et al. (2018) para el VSM, se analizan las diferencias macroscópicas, petrográficas, geoquímicas y geocronológicas del Cinturón Occidental y del Cinturón Oriental del AMSM, agrupando los plutones que corresponden a cada cinturón en la Tabla 1 . 


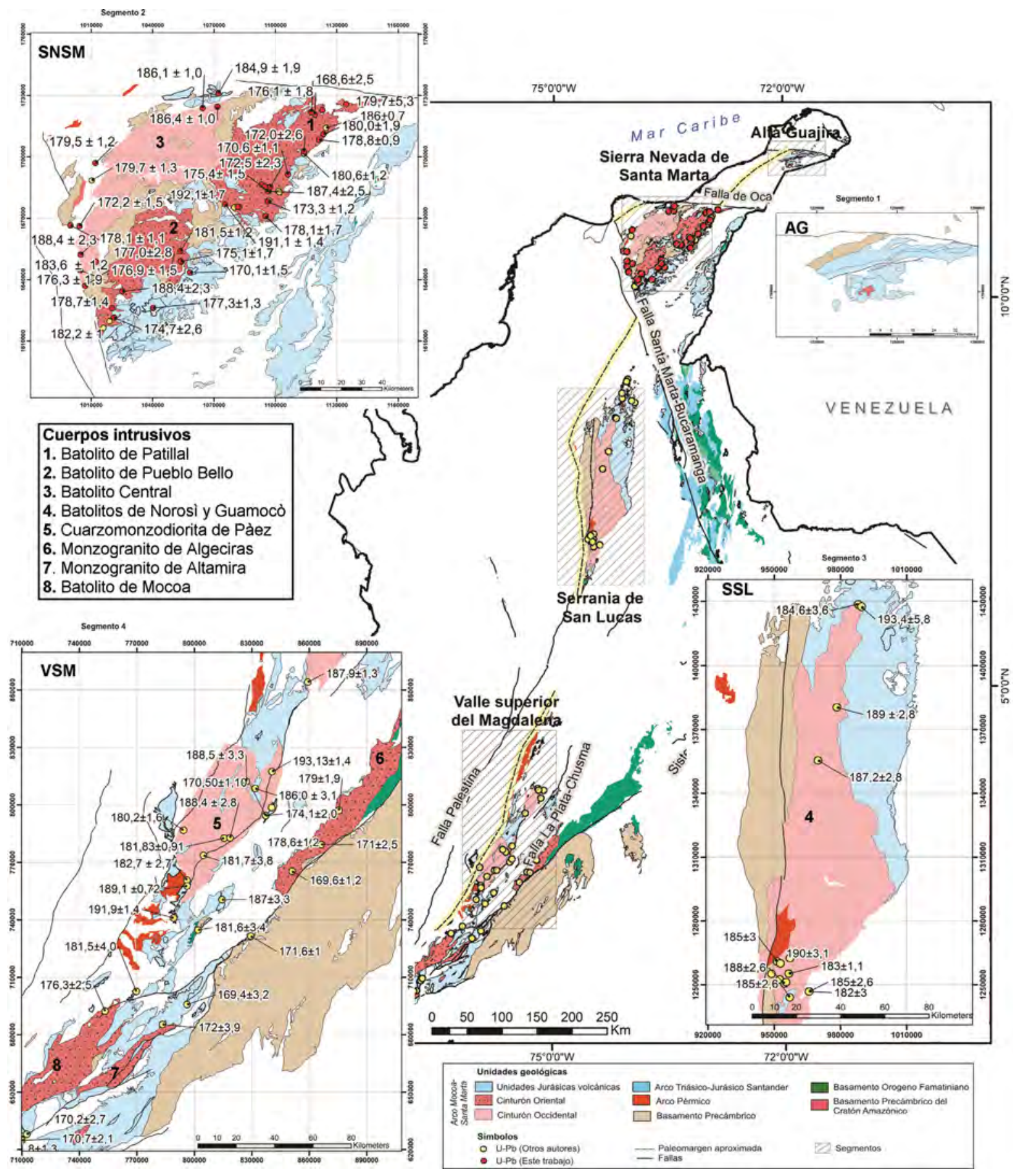

Figura 2. Distribución de segmentos y plutones que forman los cinturones Occidental y Oriental del AMSM y localización espacial de edades $\mathrm{U}-\mathrm{Pb}$. 
Tabla 1. Plutones que conforman los cinturones Occidental y Oriental del AMSM.

\begin{tabular}{|c|c|c|c|}
\hline \multicolumn{2}{|c|}{ Cinturón Occidental } & \multicolumn{2}{|c|}{ Cinturón Oriental } \\
\hline \multicolumn{4}{|c|}{ Valle Superior del Magdalena (VSM) } \\
\hline $\begin{array}{l}\text { Cuarzomonzonita de San } \\
\text { Cayetano }\end{array}$ & $\begin{array}{l}\text { Carvajal et al., 1983, } 1993 \\
\text { Bermúdez et al., } 2015\end{array}$ & Monzogranito de Algeciras & $\begin{array}{l}\text { Ferreira et al., 1998, } 2002 \\
\text { Rodríguez et al., 2015d }\end{array}$ \\
\hline $\begin{array}{l}\text { Cuarzomonzonita de An- } \\
\text { chique }\end{array}$ & $\begin{array}{l}\text { Cossio et al., } 1994 \\
\text { Arango et al., 2015a }\end{array}$ & Cuarzolatita de Teruel & Arango et al., 2015c \\
\hline $\begin{array}{l}\text { Cuarzomonzonita de Los } \\
\text { Naranjos }\end{array}$ & $\begin{array}{l}\text { Rodríguez y Fuquen, } 1989 \\
\text { Velandia et al., 2001b, } \\
\text { Rodríguez et al., 2015b }\end{array}$ & Granito de Garzón & $\begin{array}{l}\text { Velandia et al., 2001a } \\
\text { Rodríguez et al., 2015e }\end{array}$ \\
\hline $\begin{array}{l}\text { Cuarzomonzodiorita de El } \\
\text { Astillero }\end{array}$ & $\begin{array}{l}\text { Velandia et al., 2001a } \\
\text { Rodríguez et al., 2015c }\end{array}$ & Monzogranito de Altamira & Arango et al., 2015d \\
\hline Monzodiorita de Las Minas & $\begin{array}{l}\text { Velandia et al., 2001a; } \\
\text { Arango et al., 2015b }\end{array}$ & $\begin{array}{l}\text { Cuarzomonzonita de Sombre- } \\
\text { rillo }\end{array}$ & Rodríguez et al., 2018 \\
\hline Stock de Dolores & $\begin{array}{l}\text { Guerrero y Támara, } 1982 \\
\text { Cossio et al., } 1994\end{array}$ & Monzogranito de Mocoa & $\begin{array}{l}\text { Escorce, } 1977 \\
\text { González y Núñez, } 2001 \\
\text { Arango et al., 2015e }\end{array}$ \\
\hline $\begin{array}{l}\text { Cuarzomonzodiorita del } \\
\text { Páez }\end{array}$ & Zapata et al., 2015 & & \\
\hline \multicolumn{4}{|c|}{ Serranía de San Lucas (SSL) } \\
\hline Granito de Norosí & $\begin{array}{l}\text { Bogotá y Aluja, } 1981 \\
\text { Leal-Mejía, 2011; } \\
\text { González et al., 2015a, 2015b }\end{array}$ & & \\
\hline Granodiorita de Guamocó & $\begin{array}{l}\text { Leal-Mejía, 2011; } \\
\text { GEOTEC, 2003; } \\
\text { González et al., 2015b, 2015c }\end{array}$ & & \\
\hline Monzonita de Papayal & Leal-Mejía, 2011 & & \\
\hline \multicolumn{4}{|c|}{ Sierra Nevada de Santa Marta (SNSM) } \\
\hline Batolito Central & $\begin{array}{l}\text { Tschanz et al., 1969a } \\
\text { Rodríguez et al., 2019b }\end{array}$ & $\begin{array}{l}\text { Batolito de Pueblo Bello } \\
\text { Batolito de Atánquez } \\
\text { Batolitos de Patillal }\end{array}$ & $\begin{array}{l}\text { Tschanz et al., 1969a } \\
\text { Colmenares et al., 2007 } \\
\text { Rodríguez et al., 2019b }\end{array}$ \\
\hline \multicolumn{4}{|c|}{ Alta Guajira (AG) } \\
\hline Granodiorita de Ipapure & $\begin{array}{l}\text { Radelli, } 1960 \\
\text { Rodríguez y Londoño, } 2002 \\
\text { Zuluaga et al., } 2009\end{array}$ & & \\
\hline
\end{tabular}

\section{Petrografía}

En sentido oeste-este el plutonismo del arco muestra cambios composicionales entre los dos cinturones. En el VSM el Cinturón Occidental pasa de dioritascuarzomonzodioritas - cuarzomonzonitas a monzogranitos en el Cinturón Oriental. En la SNSM el Cinturón Occidental pasa de tonalitas-granodioritas a monzogranitos y sienogranitos en el Cinturón Oriental; presentando un cambio espacial transicional en la composición (Figura 3A, 3B).
El Cinturón Occidental en el norte del VSM, está constituido por stocks de cuarzomonzonitas y monzonitas y en el sur varía a stocks y batolitos de cuarzomonzodioritas, dioritas y ocasionalmente charnoquitas con plagioclasa $(\mathrm{Pl})+$ feldespato alcalino $(\mathrm{Kfs})+$ cuarzo $(\mathrm{Qtz})(<20 \%) \pm$ hornblenda $(\mathrm{Hbl}) \pm$ biotita (Bt) \pm clinopiroxeno $(\mathrm{Cpx}) \pm$ ortopiroxeno (Opx). Presentan minerales accesorios como opacos (Op), apatito (Ap), circón (Zrn) y titanita (Ttn) (Rodríguez et al., 2018) (Figura 3A). En la SSL corresponden a cuerpos batolíticos de granodioritas y 
monzogranitos con subordinadas facies de tonalitas, charnoquitas y cuarzomonzodioritas, constituidos por $\mathrm{Pl}+\mathrm{Kfs}+\mathrm{Qtz}(\geq 20 \%) \pm \mathrm{Hbl} \pm \mathrm{Bt} \pm \mathrm{Cpx} \pm \mathrm{Opx}$, con minerales accesorios como opacos, apatito y circón. En la SNSM corresponde a un cuerpo batolítico compuesto por tonalitas y granodioritas con monzogranitos y cuarzodioritas subordinadas; está constituido por Pl $+\mathrm{Kfs}+\mathrm{Qtz}(\geq 20 \%)+\mathrm{Hbl}+\mathrm{Bt}$ y como minerales accesorios tiene opacos, apatito, circón y titanita. En la AG se presenta un stock de composición tonalítica y granodiorítica, constituidos por $\mathrm{Pl}+\mathrm{Kfs}+\mathrm{Qtz}(\geq 20 \%)$ $+\mathrm{Hbl}+\mathrm{Bt}$ y como minerales accesorios tienen opacos, apatito, circón y titanita (Figura 3A).

Las rocas de los plutones del Cinturón Occidental muestran variación en la composición modal en sentido sur-norte: predominan hacia el sur, en el VSM, los plutones de composición cuarzomonzodiorítica a cuarzomonzonítica con menores contenidos de cuarzo $\leq 20 \%$ y mayores contenidos de minerales máficos como hornblenda y biotita con presencia ocasional de clinopiroxeno y ortopiroxeno. En el sector central, SSL, los plutones son principalmente tonalíticos, granodioríticos hasta monzograníticos, tienen mayores contenidos de cuarzo $\geq 20 \%$ y disminuyen los minerales máficos como hornblenda y biotita y ocasionalmente se presenta clinopiroxeno y ortopiroxeno en las rocas menos diferenciadas. En el sector norte, SNSM y AG, los plutones están constituidos principalmente por tonalitas y granodioritas, con cuarzo $>20 \%$ y una disminución de los minerales máficos como hornblenda y biotita.

El Cinturón Oriental solo aparece en el VSM y la SNSM, y no se presenta en la SSL y la AG debido a la menor información geológica y a la cubierta volcánica del AMSM que no permite que afloren los plutones orientales. Macroscópicamente corresponden a granitos rosados. En el VSM, lo conforman stocks y batolitos principalmente compuestos por monzogranitos y en menor proporción rocas monzoníticas, con $\mathrm{Kfs}+\mathrm{Pl}+$ $\mathrm{Qtz}(>20 \%)+\mathrm{Bt} \pm \mathrm{Hbl} \pm \mathrm{Cpx}, \mathrm{y}$ minerales accesorios como opacos, apatito, circón, titanita \pm allanita (Rodríguez et al., 2018). En la SNSM aflora en la vertiente oriental cuerpos batolíticos de monzogranitos y sienogranitos, con escasas granodioritas. Estos plutónes están constituidos por Qtz $(\geq 20 \%)+\mathrm{Pl}+\mathrm{Kfs}$ $+\mathrm{Bt} \pm \mathrm{Hbl}$, como minerales accesorios tiene opacos, apatito, circón y titanita (Figura 3B, Tabla TS1).
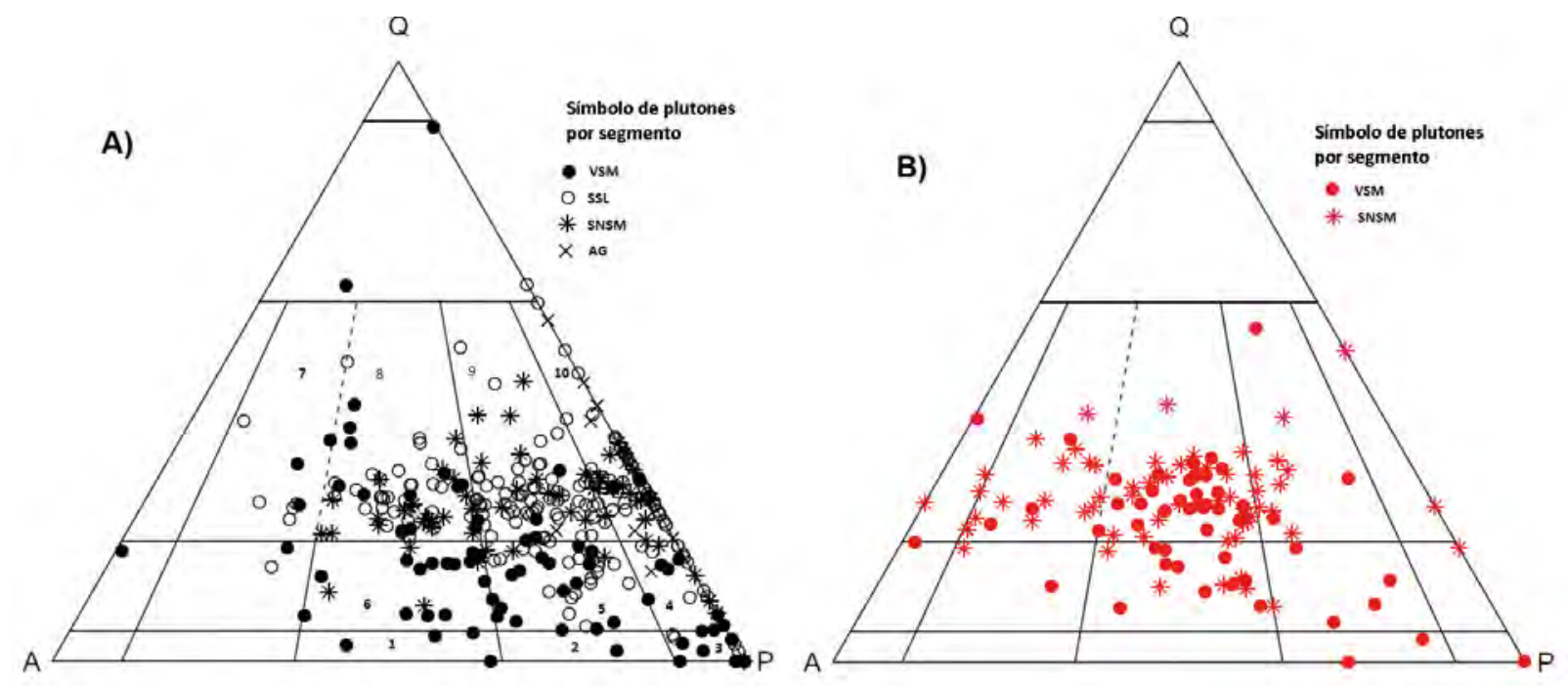

Figura 3. Composición modal de los plutones del AMSM a partir del Diagrama de Clasificación QAP de Streckeisen (1976). A. Plutones del Cinturón Occidental en los segmentos VSM, SSL, SNSM y AG. B. Plutones del Cinturón Oriental en los segmentos VSM y SNSM. Campos del diagrama de Streckeisen (1976) 1) monzonita, 2) monzodiorita, 3) diorita, 4) cuarzo diorita, 5) cuarzo monzodiorita, 6) cuarzo monzonita, 7) sienogranito, 8) monzogranito, 9) granodiorita, 10) tonalita, 11) granito de feldespato alcalino, 12) sienita de feldespato alcalino y 13) cuarzosienita. 
Las rocas del Cinturón Oriental muestran variación en la composición modal en sentido sur-norte: predominan hacia el sur en el VSM, los plutones de composición monzogranítica y subordinada monzonítica, y en la SNSM los plutones de composición granodiorítica, monzogranítica y sienogranítica, mostrando un mayor enriquecimiento en feldespato de potasio (Figura 3).

\section{Litogeoquímica}

Un total de 191 análisis geoquímicos de óxidos mayores, elementos traza y tierras raras (REE) han sido obtenidos de los cuerpos plutónicos Jurásicos en los segmentos VSM, SSL, SNSM y AG, incluyendo los datos publicados por González et al. (2015a, 2015b, 2015c), Ríos-Blandón (2016), Rodríguez et al. (2018) y Quandt et al. (2018) y los obtenidos para este trabajo (Tabla TS2).

Los granitoides jurásicos presentan disminución de $\mathrm{TiO}_{2}, \mathrm{Al}_{2} \mathrm{O}_{3}, \mathrm{MgO}, \mathrm{CaO}$, FeOt y $\mathrm{P}_{2} \mathrm{O}_{5}$, y aumento de $\mathrm{K}_{2} \mathrm{O}$ y $\mathrm{Na}_{2} \mathrm{O}$ con el aumento de $\mathrm{SiO}_{2}$ y dispersión de los contenidos de $\mathrm{K}_{2} \mathrm{O}$ y $\mathrm{Na}_{2} \mathrm{O}$ (Figura 4). Las rocas de los plutones del Cinturón Oriental presentan predominio de valores menores de $\mathrm{TiO}_{2}, \mathrm{Al}_{2} \mathrm{O}_{3}, \mathrm{MgO}, \mathrm{CaO}$ y FeOt respecto a las rocas del Cinturón Occidental. En el VSM el contenido de $\mathrm{SiO}_{2}$ y $\mathrm{K}_{2} \mathrm{O}$ aumenta de oeste a este. Ambos cinturones en conjunto presentan un patrón continúo de diferenciación magmática.

Los contenidos de $\mathrm{TiO}_{2}$ son mayores en el Cinturón Occidental con predominio de contenidos entre 0,6 y $1,2 \%$, mientras en el Cinturón Oriental los contenidos predominan entre 0,1 y $0,5 \%$, además, los valores de $\mathrm{TiO}_{2}$ son ligeramente más altos y más bajos en $\mathrm{Al}_{2} \mathrm{O}_{3}$ en la SSL. Un comportamiento similar se presenta para el $\mathrm{CaO}$, en el Cinturón Occidental los contenidos son más altos que en el Cinturón Oriental con valores predominantes entre 3 y $8 \%$ y entre 1 y $4 \%$ respectivamente. Aunque el $\mathrm{Na}_{2} \mathrm{O}$ y el $\mathrm{K}_{2} \mathrm{O}$ son móviles, hay leve incremento de estos dos óxidos con el aumento de $\mathrm{SiO}_{2}$ del Cinturón Occidental al Cinturón Oriental. Los diagramas de Harker sugieren que la diferenciación magmática del AMSM se dio de manera continua o que la evolución del arco fue progresiva en el tiempo.

El contenido de $\mathrm{SiO}_{2}$ aumenta de sur a norte y de oeste a este en el arco, con mayores frecuencias de valores en $\mathrm{SiO}_{2}$ para los plutones del Cinturón Occidental del VSM en el rango entre 60 y $65 \%$ de $\mathrm{SiO}_{2}$, en la SSL entre 60 y $70 \%$ de $\mathrm{SiO}_{2}$, en la SNSM entre 70 y $75 \%$ de $\mathrm{SiO}_{2}$ y para los de la AG entre 65 y $70 \%$ de $\mathrm{SiO}_{2}$.
Para los plutones del Cinturón Oriental, la frecuencia de valores de $\mathrm{SiO}_{2}$ varía en el VSM y la SNSM en un rango entre 70 y $80 \%$ (Figura 5).

Los plutones del Cinturón Occidental son menos diferenciados, más ricos en $\mathrm{FeO}$ y $\mathrm{MgO}$ que los plutones del Cinturón Oriental que se enriquecen en álcalis, con un empobrecimiento en $\mathrm{FeO}$ y $\mathrm{MgO}$ continuo de sur a norte y de oeste a este, todos pertenecen a las series subalcalina y calcoalcalina (Figuras 6A y 6B). Los plutones son metaluminosos y unas cuantas muestras grafican dentro del campo peraluminoso (Figura 6C); las rocas del Cinturón Occidental mayoritariamente son metaluminosas y las del Cinturón Oriental están repartidas entre metaluminosas y peraluminosas, ubicándose la mayoría de las rocas dentro del campo de los granitos Tipo I por debajo del límite con los granitos Tipo S (Figura 6C), y dentro de las franjas de granitos calcoalcalinos y alcalino cálcico, con escasas muestras en los campos alcalino y cálcico (Figura 6D).

Los granitoides de los cinturones Occidental y Oriental tienen patrones comparables de elementos traza normalizados al N-MORB, con anomalías negativas de Nb, Ti y $\mathrm{P}$, y anomalías positivas y valores altos de $\mathrm{Cs}, \mathrm{Rb}, \mathrm{Ba}$, Th, $\mathrm{K}$ y $\mathrm{Pb}$, patrón normal en ambientes de arco magmático de margen continental (Figura 7) (Pearce, 1996, 2008). El patrón de las tierras raras normalizadas a los valores del condrito de Nakamura (1974) tiene pendiente negativa, con enriquecimiento en tierras raras livianas (LREE) y empobrecimiento progresivo hacia las tierras raras pesadas (HREE) (Figura 8). Se observa una diferencia en el contenido de Zr del Batolito de Norosí en el segmento SSL, con relación a los demás cuerpos plutónicos del arco, con valores entre 26,6 ppm y 62,8 ppm, mientras el resto de plutones presenta valores de $\mathrm{Zr}$ mayores a 100 ppm (Tabla TS2). Los plutones del Cinturón Oriental alcanzan valores absolutos más elevados de los LREE que los del Cinturón Occidental, comportamiento normal en rocas con contenidos más altos de $\mathrm{K}$. Además hay una dispersión mayor de los HREE en los plutones del Cinturón Occidental.

La relación $(\mathrm{La} / \mathrm{Yb})_{\mathrm{N}}$ en los plutones del Cinturón Occidental varían entre 5 y 16, la mayoría de rocas tienen valores inferiores a 10; en el Cinturón Oriental varía entre 5,7 y 21, siendo la mayoría de valores mayores a 9, y sugiriendo aumento en la diferenciación magmática en el sentido oeste - este. La relación $\mathrm{Eu} / \mathrm{Eu}^{*}$ de las rocas de los dos cinturones de plutones varían entre 0,7 y 1,8 . La relación $(\mathrm{Ce} / \mathrm{Yb})_{\mathrm{N}}$ que representa la relación entre LREE/HREE normalizada al condrito de 
Nakamura (1974), presenta valores entre 3,3 y 10,8 para la mayoría de rocas. La suma de elementos de las tierras raras ( $\left.\sum \mathrm{REE}\right)$, presenta los menores valores para los plutones del Cinturón Occidental de la SSL y la SNSM, con valores entre 40 y 138 ppm, mientras los plutones orientales y occidentales del VSM y los orientales de la SNSM la $\sum$ REE varían entre 111 y 285 ppm.
El diagrama de discriminación de ambiente tectónico de Condie y Kröner (2013), muestra que las rocas de los plutones del arco jurásico caen dentro del campo de los arcos continentales (Figura 9).
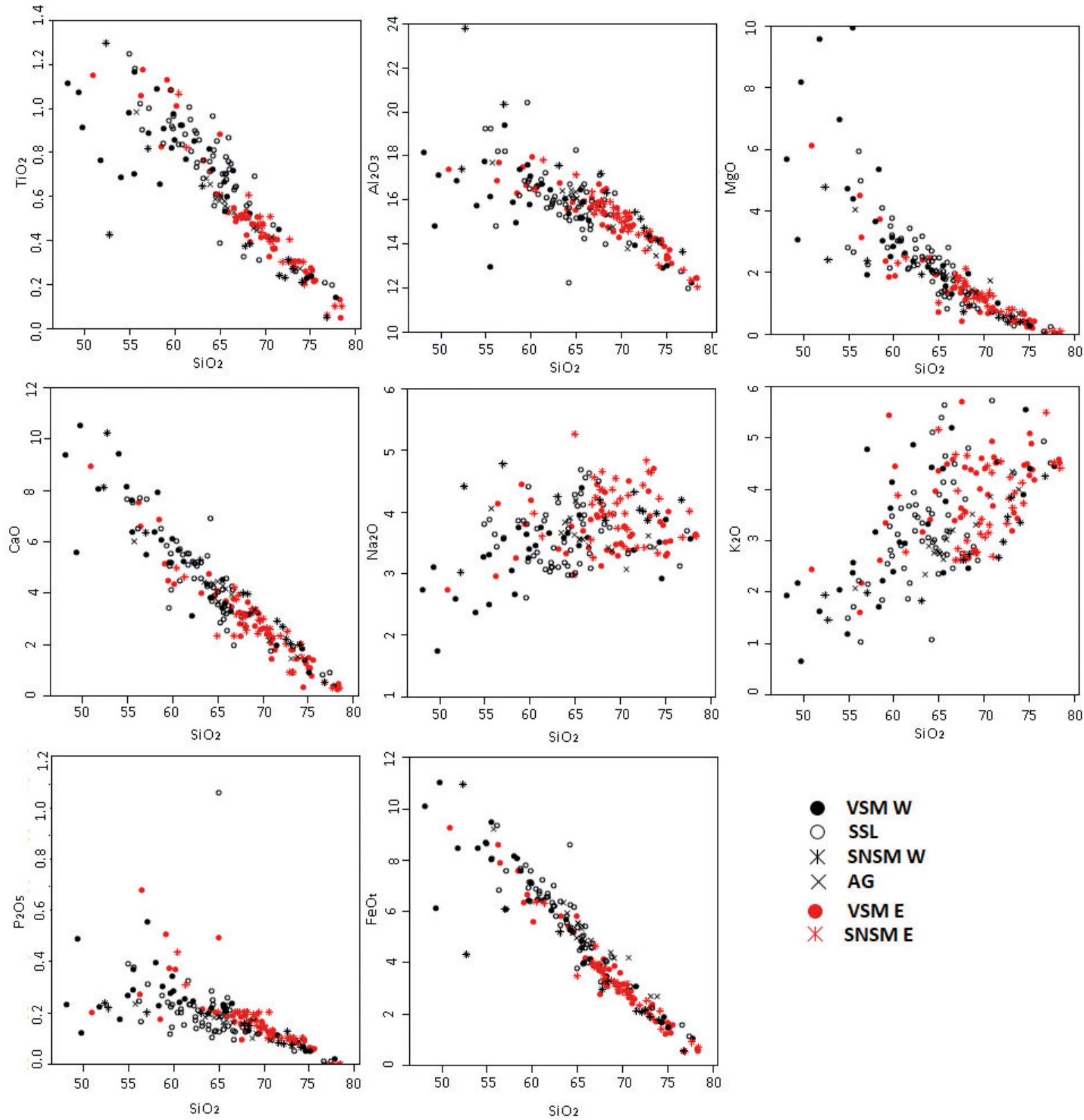

Figura 4. Diagramas tipo Harker para rocas plutónicas de los cinturones Occidental (negro) y Oriental (rojo) del AMSM en el VSM, SSL, SNSM y AG. 

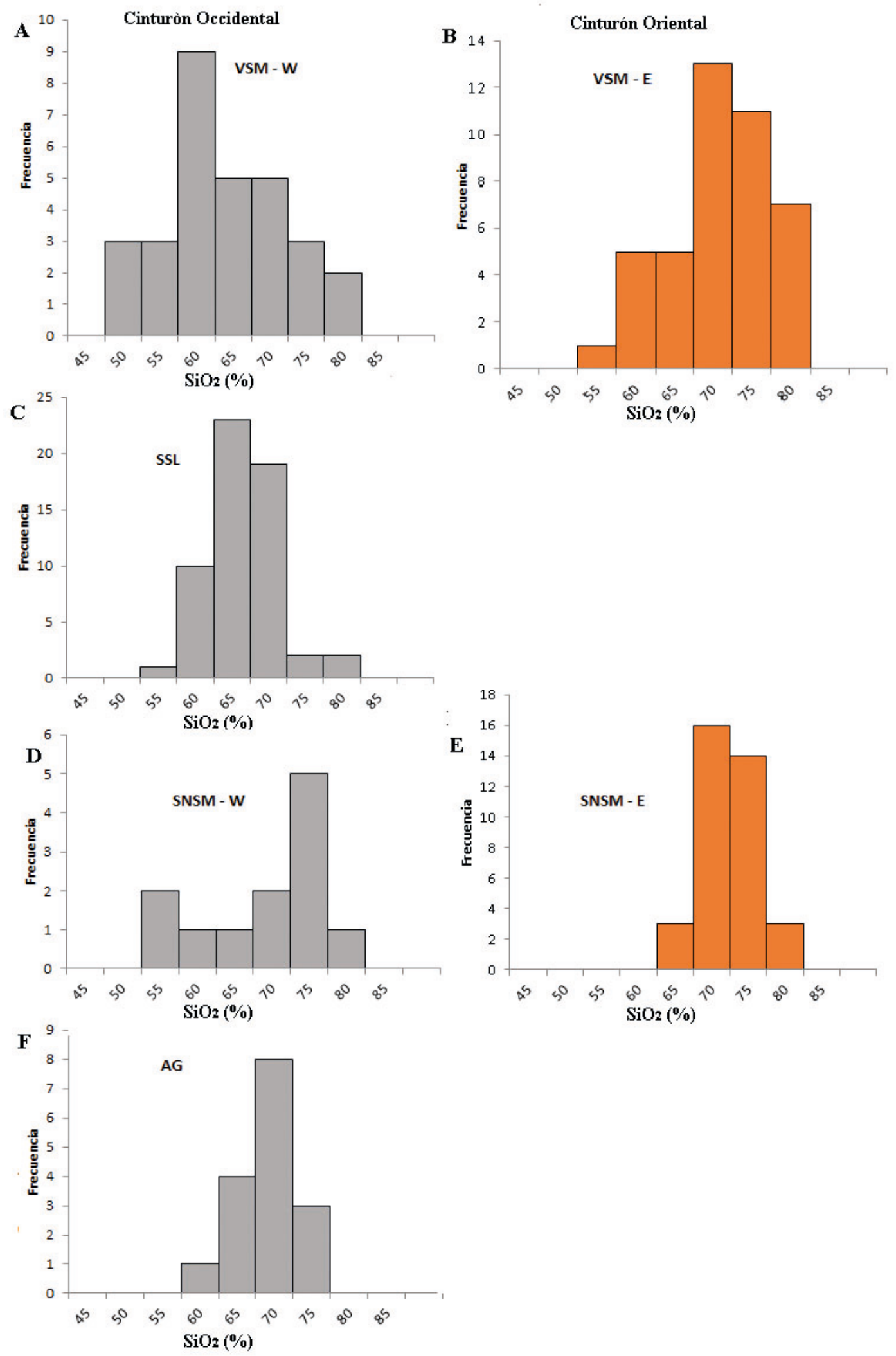

Figura 5. Histogramas de frecuencia de $\mathrm{SiO}_{2}$, para plutones de diferentes segmentos del AMSM. A. y B. VSM, C. SSL, D. y E. SNSM y F. AG. 

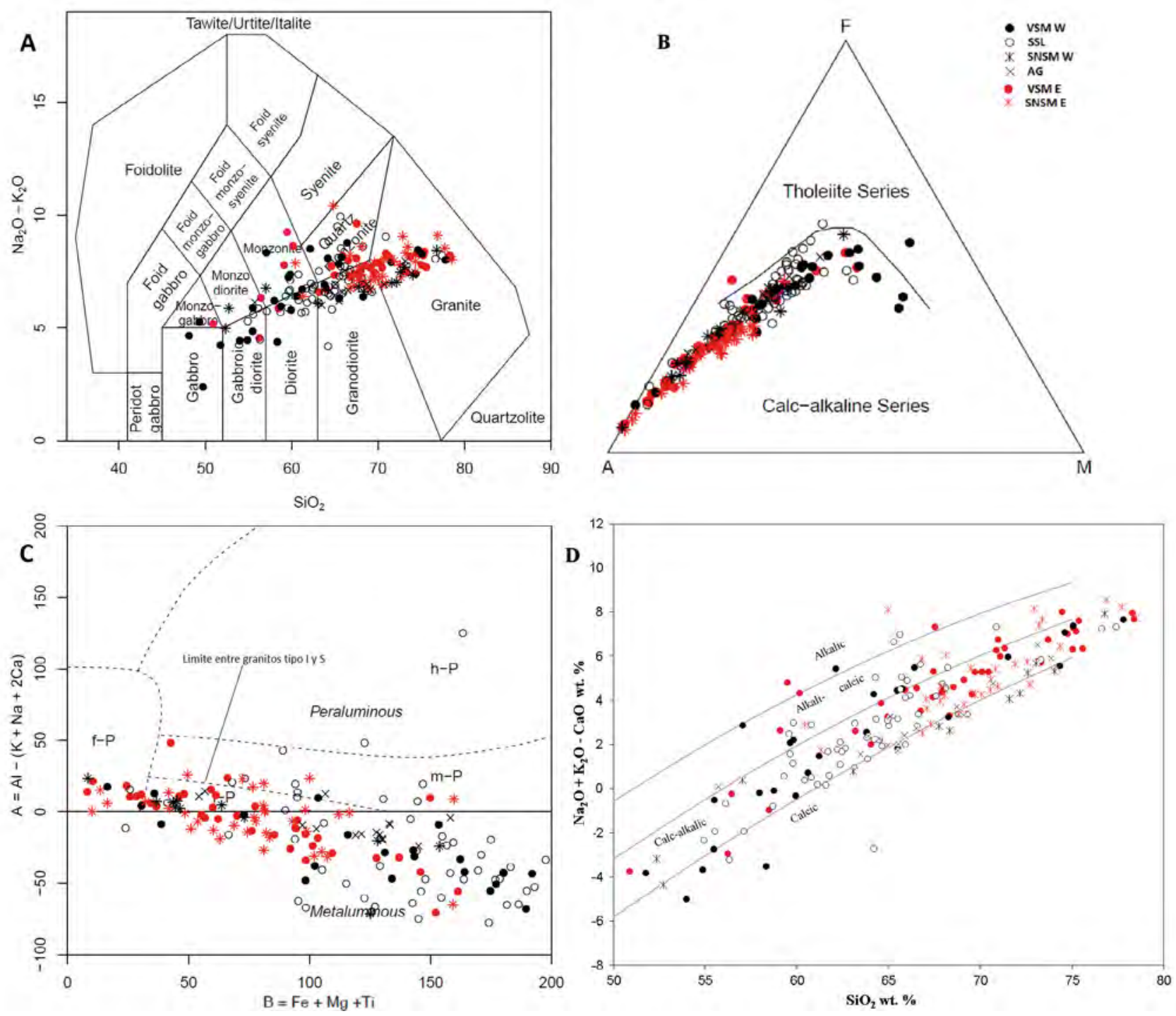

Figura 6. Diagramas de clasificación de rocas de los plutones jurásicos del VSM, SSL, SNSM y AG. A. Diagrama TAS de Middlemost (1994). B. Diagrama AFM de Irvine y Baragar (1971). C. Diagrama de Villaseca et al. (1998). D. Diagrama de clasificación de granitoides de Frost et al. (2001). 

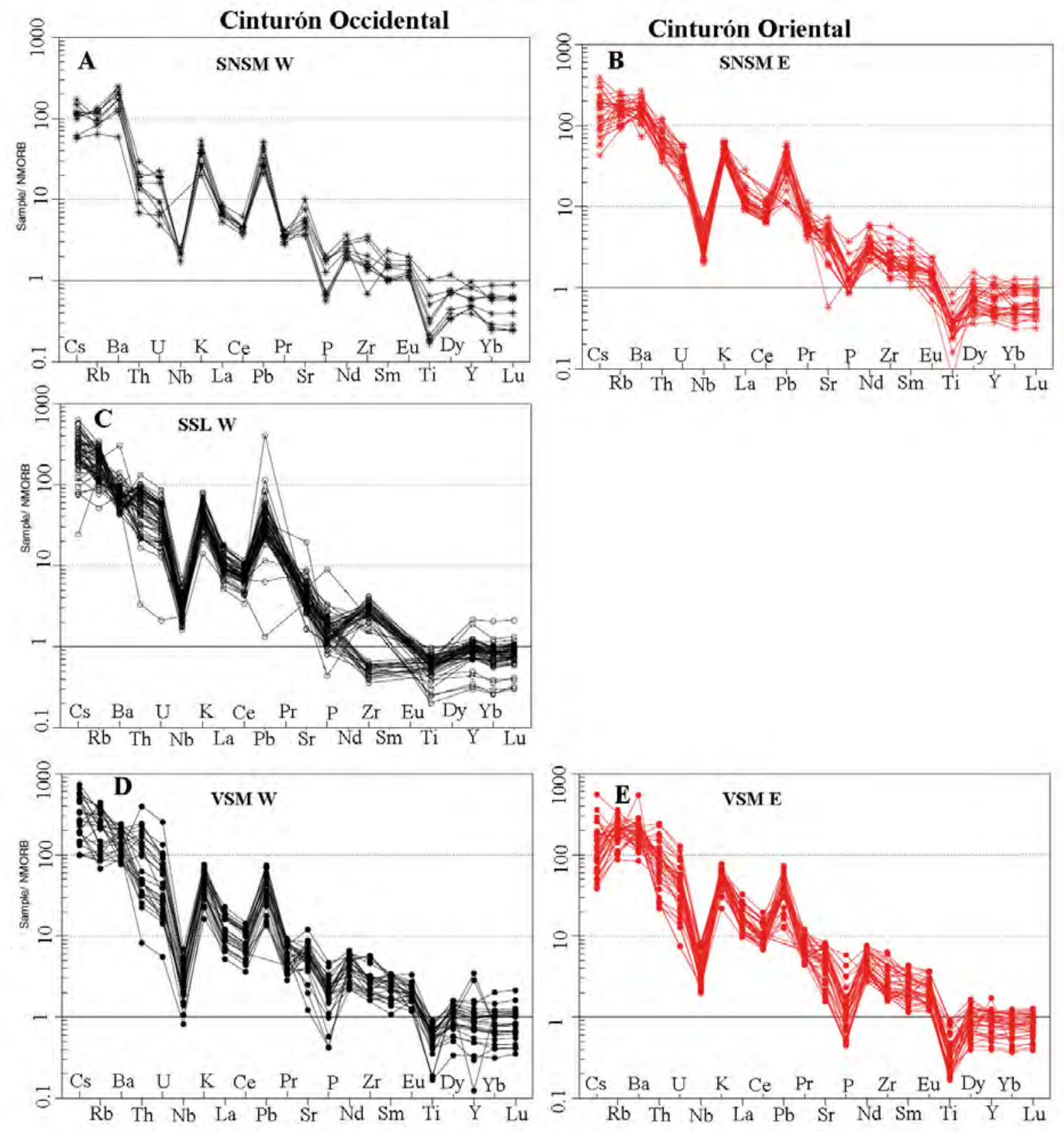

Figura 7. Diagramas multielementales para los plutones Jurásicos del VSM, SSL, SNSM; normalizados a los valores de NMORB (Pearce, 1996). A. Plutones del Cinturón Occidental de la SNSM. B. Plutones del Cinturón Oriental de la SNSM. C. Plutones del Cinturón Occidental de la SSL. D. Plutones del Cinturón Occidental del VSM. E. Plutones del Cinturón Oriental del VSM. 
Aportes al conocimiento del plutonismo del Arco Mocoa-Santa Marta durante el Jurásico Temprano-Medio, en la margen noroccidental de los Andes, Colombia
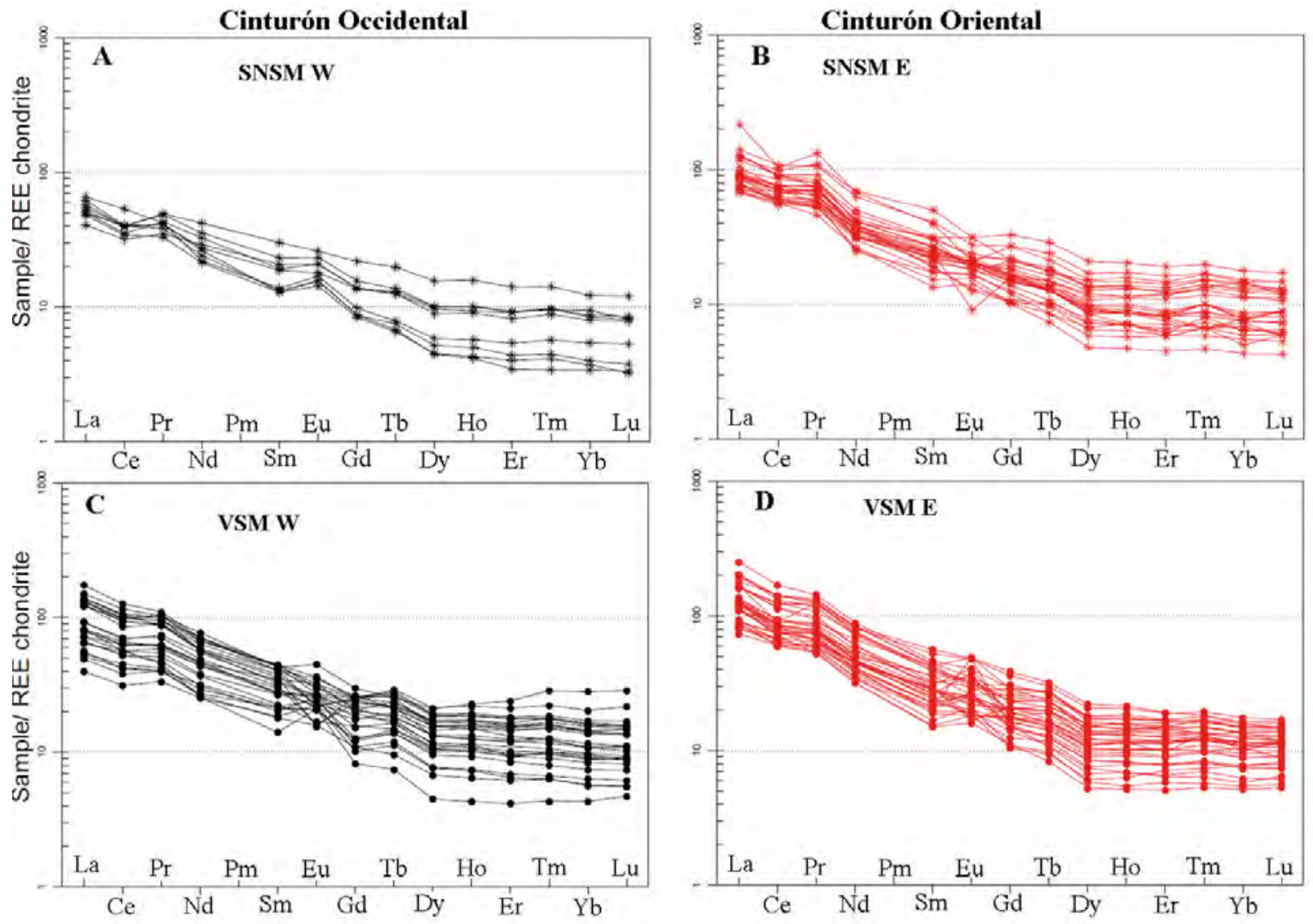

Figura 8. Diagramas multielementales para los plutones Jurásicos del VSM, SNSM; normalizados a los valores del condrito según Nakamura (1974). A. Plutones del Cinturón Occidental de la SNSM. B. Plutones del Cinturón Oriental de la SNSM. C. Plutones del Cinturón Occidental del VSM. D. Plutones del Cinturón Oriental del VSM.

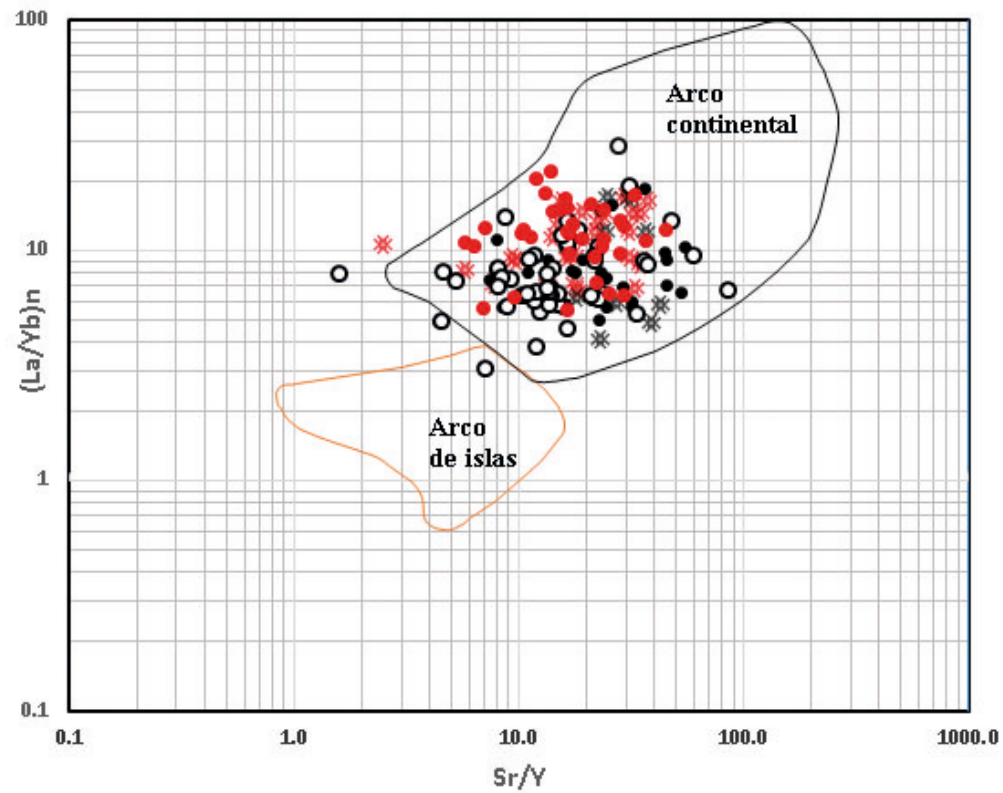

Figura 9. Diagrama de discriminación tectónica $(\mathrm{La} / \mathrm{Yb})_{\mathrm{N}}$ vs $\mathrm{Sr} / \mathrm{Y}$ de Condie y Kröner (2013) para rocas plutónicas del AMSM, normalizadas contra el valor del condrito según Nakamura (1974). 


\section{Geocronología}

Para el análisis geocronológico del plutonismo del AMSM se utilizaron 115 edades U-Pb LA-ICPMS en circones y dos (2) por U-Pb SHRIMP, correspondientes a los principales plutones de los segmentos VSM, SSL y SNSM. De las 117 dataciones, treinta y ocho (38) son nuevas y la interpretación detallada y los gráficos de cada una de ellas se puede encontrar en el trabajo de Rodríguez et al. (2019b), para los plutones de la SNSM. Setenta y siete edades (77) fueron compiladas de otros trabajos (Bustamante et al., 2010; Leal-Mejía, 2011; González et al., 2015a, 2015b, 2015c; Rodríguez et al., 2018). Las edades se resumen en la Tabla TS3.

La cristalización de los plutones jurásicos de la SNSM se dio en el intervalo comprendido entre 193 y 164 $\mathrm{Ma}$, que representa el espectro de cristalización de los plutones en el AMSM. En la SSL el intervalo de cristalización varió de 192 a 173 Ma y en el VSM de 193 a $168 \mathrm{Ma}$, siendo prácticamente el mismo intervalo para la SNSM y el VSM donde están representados los dos cinturones de plutones, mientras en la SSL solo se presenta el Cinturón Occidental.

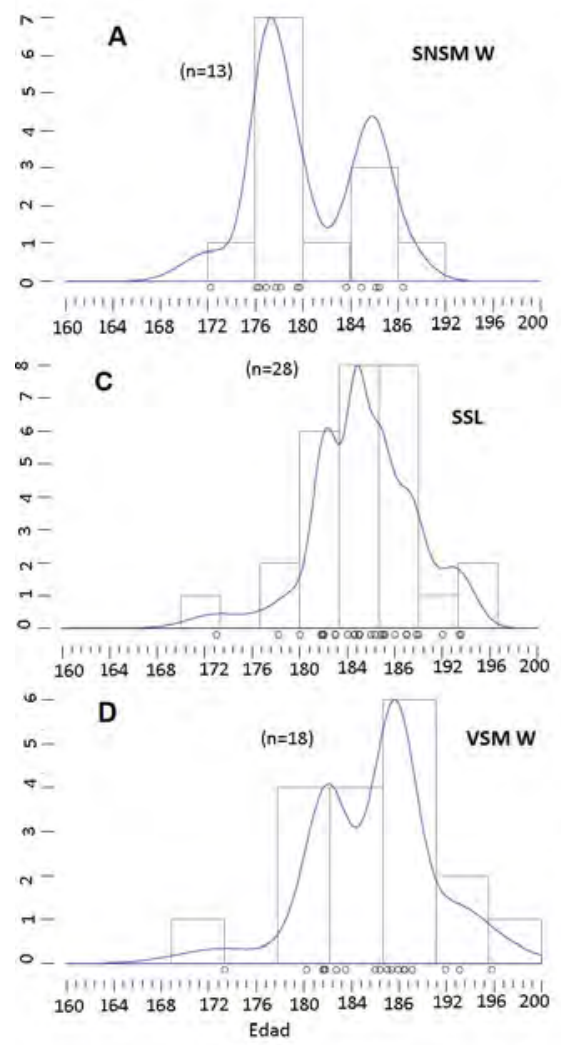

En la SNSM aunque se reconocen los dos cinturones espacialmente hay superposición de edades con una tendencia general de cristalización más joven en los plutones del Cinturón Oriental. En la SSL los plutones presentan una sola posición espacial y en el VSM, las edades más jóvenes corresponden a los plutones del Cinturón Oriental.

Las edades de cristalización del Cinturón Occidental de la SNSM varían entre 188 y 172 Ma (n=13), con picos máximos a 186 y 176 Ma (Figura 10A). En el Cinturón Oriental de la SNSM las edades varían entre 192 y $164 \mathrm{Ma}(\mathrm{n}=36)$, con picos máximos a 189, 179 y $170 \mathrm{Ma}$ (Figura 10B). Las edades de cristalización de los plutones jurásicos de la SSL varían entre 192 y 173 Ma $(n=28)$, con picos máximos a 185 y 182 Ma (Figura 10C). Las edades de cristalización del Cinturón Occidental del VSM varían entre 193 y 173 Ma (n=18), con picos máximos a 188 y 182 Ma y las edades de cristalización del Cinturón Oriental del VSM varían entre 182 y 168 Ma (n=20), con picos máximos de cristalización a 179 y 170 Ma (Figuras 10D, 10E).
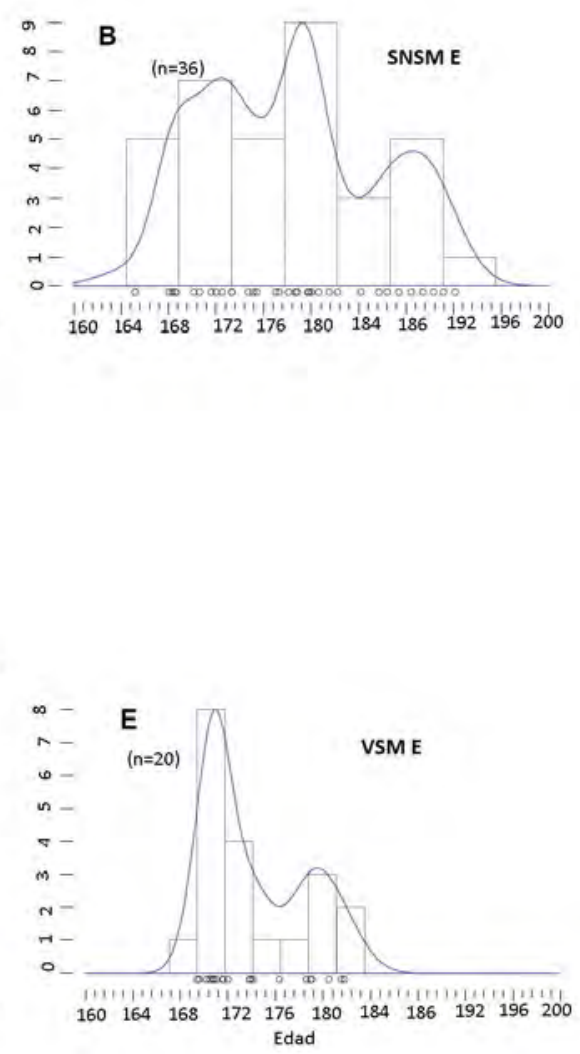

Figura 10. Diagramas de estimación de densidad de Kernel a partir de las edades de cristalización U-Pb, de los plutones Jurásicos. A. Cinturón Occidental de la SNSM. B. Cinturón Oriental de la SNSM. C. SSL. D. Cinturón Occidental del VSM. E. Cinturón Oriental del VSM. 
Los eventos principales de cristalización magmática se determinan a partir de las edades U-Pb del AMSM, se muestran los episodios de mayor cristalización en los gráficos de la Figura 9 para cada segmento, y a nivel particular algunos cuerpos batolíticos y stocks se formaron a partir de la cristalización de varios pulsos. Los episodios de cristalización más viejos ocurrieron en los plutones del Cinturón Occidental y los más jóvenes en los plutones del Cinturón Oriental. En general las edades U-Pb del AMSM sugieren al menos cuatro pulsos: un primer pulso de cristalización alrededor de 193 Ma representado por las primeras edades de cristalización en los tres segmentos (SNSM, SSL y VSM), un segundo pulso entre 188 y $186 \mathrm{Ma}$, bien marcado en la SNSM y el VSM y de 186 a 184 Ma en la SSL, un tercer pulso entre 181 y 179 Ma en la SNSM, más discreto a 182 Ma en la SSL y de 183 a 181 Ma en el VSM, el cuarto pulso ocurre alrededor de 172 y 173 Ma en la SNSM, no está representado en la SSL y está bien establecido en el VSM entre 168 y $170 \mathrm{Ma}$. El registro de edades más jóvenes a 172 Ma, se presenta únicamente en las rocas pertenecientes al Cinturón Oriental.

\section{Discusión}

\section{Distribución espacial del Arco Jurásico Mocoa-Santa Marta (AMSM)}

El análisis de los datos nuevos y compilados presentados en este estudio, permiten caracterizar el magmatismo del AMSM que intruye el basamento Neoproterozoico del Orógeno Putumayo y a los plutones del Arco Pérmico, que posteriormente a la formación del AMSM fueron separados en cuatro segmentos: el segmento más al sur del AMSM en Colombia se encuentra en el VSM, donde afloran fragmentos de basamento Neo-proterozoico representados por el Grupo Garzón, los neises graníticos de Mancagua y Guapotón, las Metamórfitas de Las Minas y el Granito de El Recreo (Kroonenberg y Diederix, 1982; Rodríguez, 1995a, 1995b; Velandia et al., 1996, 2001a, 2001b; Rodríguez et al., 2003; Jiménez-Mejía et al., 2006; Ibáñez-Mejía et al., 2011, 2015). Estas unidades están parcialmente cubiertas por secuencias sedimentarias marinas de edad Paleozoica (Stibane y Forero, 1969; Villarroel y Mojica, 1988; Mojica et al., 1988; Velandia et al., 1999, 2001a). Además, se presentan plutones de un Arco Pérmico, como el Granito de La Plata (Rodríguez, 1995a; Rodríguez et al., 1998, 2017a; Velandia et al., 2001a; Leal-Mejía, 2011), el Stock Granítico de Rovira (Núñez et al., 1984a, 1984b; Villagómez, 2010; Cochrane, 2013) y el Granito de Ortega (Rodríguez et al., 2019a); estos cuerpos están suprayacidos por calizas marinas y sedimentos clásticos del Triásico como las formaciones Luisa y Payandé (Geyer, 1973; Cediel et al., 1980; Mojica, 1980; Núñez et al., 1984b; Rodríguez et al., 2019a, 2020). Plutones y rocas volcánicas (Formación Saldaña) del Jurásico Temprano y Medio intruyen y cubren las rocas metamórficas Neo-proterozoicas, los sedimentos paleozoicos y triásicos y los plutones del Arco Pérmico. Hacia el occidente estas unidades son limitadas por el Batolito de Ibagué (de edad Jurásico Superior a Cretácico temprano (Bustamante et al., 2016; Rodríguez et al., 2017b, 2020), y por unidades metamórficas del Jurásico tardío como el Complejo Cajamarca, los Neises y Anfibolitas de Tierradentro y el Complejo La Cocha-Río Téllez (Blanco-Quintero et al., 2014; Zapata-García et al., 2017; Rodríguez et al., 2017b, 2019a, 2020), que representan en conjunto el límite occidental del Terreno Chibcha. Se considera que la sutura entre el terreno Chibcha y terrenos metamórficos más jóvenes que afloran al occidente en la Cordillera Central de Colombia, fue amalgamada por la intrusión del Batolito de Ibagué al tiempo que ocurría la colisión con el Terreno Tahamí y continuó su intrusión ligeramente después de formar el Orógeno Jurásico de Tierradentro (Rodríguez et al., 2017b, 2020).

En la SSL, el basamento Neo-proterozoico está representado por el Neis de San Lucas (Cuadros, 2012; Cuadros et al., 2014), incluye neises cuarzofeldespáticos, anfibolitas y mármoles (Feininger et al., 1972; Bogotá y Aluja, 1981). Se presentan relictos de sedimentos Paleozoicos como la Formación La Cristalina (Botero, 1940; Feininger et al., 1972), aflora un plutón Carbonífero denominado Stock de El Carmen (Leal-Mejía, 2011), y cuerpos deformados del Arco Pérmico (e.g. Neis de Nechí) e intrusivos menores (e.g. Diorita de Remedios) (Restrepo et al., 2011; Leal-Mejía, 2011; Rodríguez et al., 2014, 2020). Además, plutones y rocas volcánicas del Jurásico Inferior a Medio (e.g. batolitos de Norosí y Guamocó) (Ordóñez-Carmona et al., 2009; Leal-Mejía, 2011) y la Formación Noreán (Clavijo, 1995; Royero, 1996; González et al., 2015a, 2015b, 2015c). Al occidente, el límite del basamento Neo-proterozoico (Terreno Chibcha) lo constituye la Falla del Nus y el Batolito de Segovia de la misma edad que el Batolito de Ibagué (Leal-Mejía, 2011), probablemente emplazado en rocas metamórficas del Jurásico Superior (Rodríguez et al., 2020). 
Más al norte la SNSM está constituida por fragmentos de basamento Neo-proterozoico como la Granulita de Los Mangos y el Neis de Buritaca (Tschanz et al., 1969a, 1974; Restrepo-Pace et al., 1997; Cordani et al., 2005; Cardona et al., 2010; Ordóñez-Carmona et al., 2002; Piraquive, 2017; Rodríguez et al., 2019a), cubierto localmente por unidades sedimentarias Paleozoicas (Secuencia de la Cuchilla Carbonal, Gansser, 1955; Tschantz et al., 1969a), intruidas por plutones y cubierto por rocas volcánicas del Jurásico temprano a Medio (batolitos Central, Pueblo Bello, Patillal entre otros - Tschantz et al., 1969a, 1974). El límite occidental del AMSM es fallado y pone las rocas metamórficas Neo-proterozoicas en contacto con el Neis de Los Muchachitos y los Esquistos de San Lorenzo (Tschantz et al., 1969b, 1974) de edad Jurásico Superior (Piraquive, 2017; Rodríguez et al., 2019a). Restos de plutones del Arco Pérmico se presentan deformados tectónicamente a lo largo de la sutura occidental, como el Ortoneis de El Encanto (Cardona et al., 2010; Piraquive, 2017), junto a rocas metamórficas de edad Jurásico Superior o Triásicas del Terreno Tahamí.

En la Alta Guajira aflora el último segmento del AMSM y del Terreno Chibcha, conformado por un bloque del basamento Neo-proterozoico llamado Neis de Jojoncito (Álvarez, 1967), junto a sedimentos marinos de la Formación Uipana y el Grupo Cosinas (Rollins, 1965; Rodríguez y Londoño, 2002) y rocas volcánicas como la Riodacita de Ipapure - Cerro La Teta (Radelli, 1962; Rodríguez y Londoño, 2002; Zuluaga et al., 2015), de edad Jurásico Inferior a Medio y la denominada Granodiorita de Ipapure (Radelli, 1960). El límite del Terreno Chibcha, al occidente, es la falla Santana que lo limita con el Neis de Macuira.

El Terreno Chibcha limita al oriente con el orógeno Famatiniano (macizos de Santander y Quetame) y al occidente con el Orogéno Jurásico Tierradentro (Rodríguez et al., 2018), que comprende de sur a norte los complejos La Cocha-Río Téllez, Cajamarca, los Neises y Anfibolitas de Tierradentro, partes del Neis de Los Muchachitos y los Esquistos de San Lorenzo y probablemente el Neis de Macuira (Rodríguez y Londoño, 2002; Rodríguez et al., 2020).

\section{Circones heredados en los segmentos del AMSM}

Las edades de los circones heredados son comparables en los cinturones Occidental y Oriental a lo largo de los segmentos dispersados del AMSM, situación que es de esperarse si se tiene en cuenta que se emplazaron ambos cinturones en el mismo basamento cortical. Las rocas plutónicas Jurásicas del VSM presentan circones con edades heredadas a $1561 \mathrm{Ma}$ (Meso-proterozoico), 918 Ma y 995 Ma (Neo-proterozoico), 266 Ma (Pérmico), y datos aislados a 324, 411, 1084 y $1235 \mathrm{Ma}$; edades similares en circones heredados fueron descritos para el Meso-proterozoico y el Neo-proterozoico por LealMejía (2011), siendo considerados los circones como las herencias del Cratón Amazónico y del basamento Neo-proterozoico del Terreno Chibcha. Circones heredados de edad similar han sido reportados para los intrusivos de la SSL, entre 1200 y $900 \mathrm{Ma}$, en rocas de los Batolitos de Norosí y diques de pórfido (Leal-Mejía, 2011). En la SNSM los plutones tienen herencias a 1124 Ma (Meso-proterozoico), $958 \mathrm{Ma}$ (Neo-proterozoico) y un dato de 624 Ma (Figura 11).

El AMSM se emplazó en la margen occidental de Gondwana o lo que se ha denominado en Colombia el Terreno Chibcha (Restrepo y Toussaint, 2020), constituido por un basamento Grenvilliano de neises cuarzo feldespáticos, granulitas, anfibolitas y granofels, denominado por Ibáñez-Mejía et al. (2015) como el Orógeno Putumayo, además se emplazó en rocas plutónicas de un arco previo que tiene edades de cristalización desde el Carbonífero hasta finales del Pérmico (Rodríguez et al., 2019a). Es de esperarse que las herencias del AMSM sean similares a las edades de cristalización y herencias del basamento en el cual se emplazó, en este sentido las edades y las herencias más antiguas a $0,9 \mathrm{Ga}$, probablemente se incorporaron a partir de la fusión cortical de rocas metasedimentarias del basamento Neo-proterozoico, siendo los circones aportados por el dominio cratónico más antiguo. Las edades entre 1,15 y 1,10 Ga, fueron asociadas por Ibáñez-Mejía et al. (2015) a la acreción de bordes de arco contra el margen continental, con el desarrollo de un evento metamórfico temprano en el basamento, y las edades alrededor de $0,99 \mathrm{Ga}$ las interpretaron como la incorporación de la Amazonía al núcleo de Rodinia durante la colisión contra Báltica.

La población de 266 Ma (Pérmico) presente en los plutones del VSM y vulcanitas Jurásicas de la SNSM, la interpretamos como herencia de los plutones del Arco Pérmico (Rodríguez et al., 2019a). Las edades de 324 Ma están asociados a cuerpos de edad Carbonífera como el Stock de El Carmen (Leal-Mejía, 2011). Datos aislados entre 411 y $624 \mathrm{Ma}$, son similares a las herencias descritas por Rodríguez et al. (2019a) en plutones del Arco Pérmico, que según Nova et al. (2018) corresponden a circones posiblemente de 
unidades incluidas en los bloques Mixteco y Maya de México, o de los intrusivos Paleozoicos de los Andes de Mérida. Así, los circones heredados obtenidos en rocas del AMSM obedecen al basamento cortical sobre el cual están emplazados los plutones y a la incorporación de estos circones por fusión de las rocas de caja.

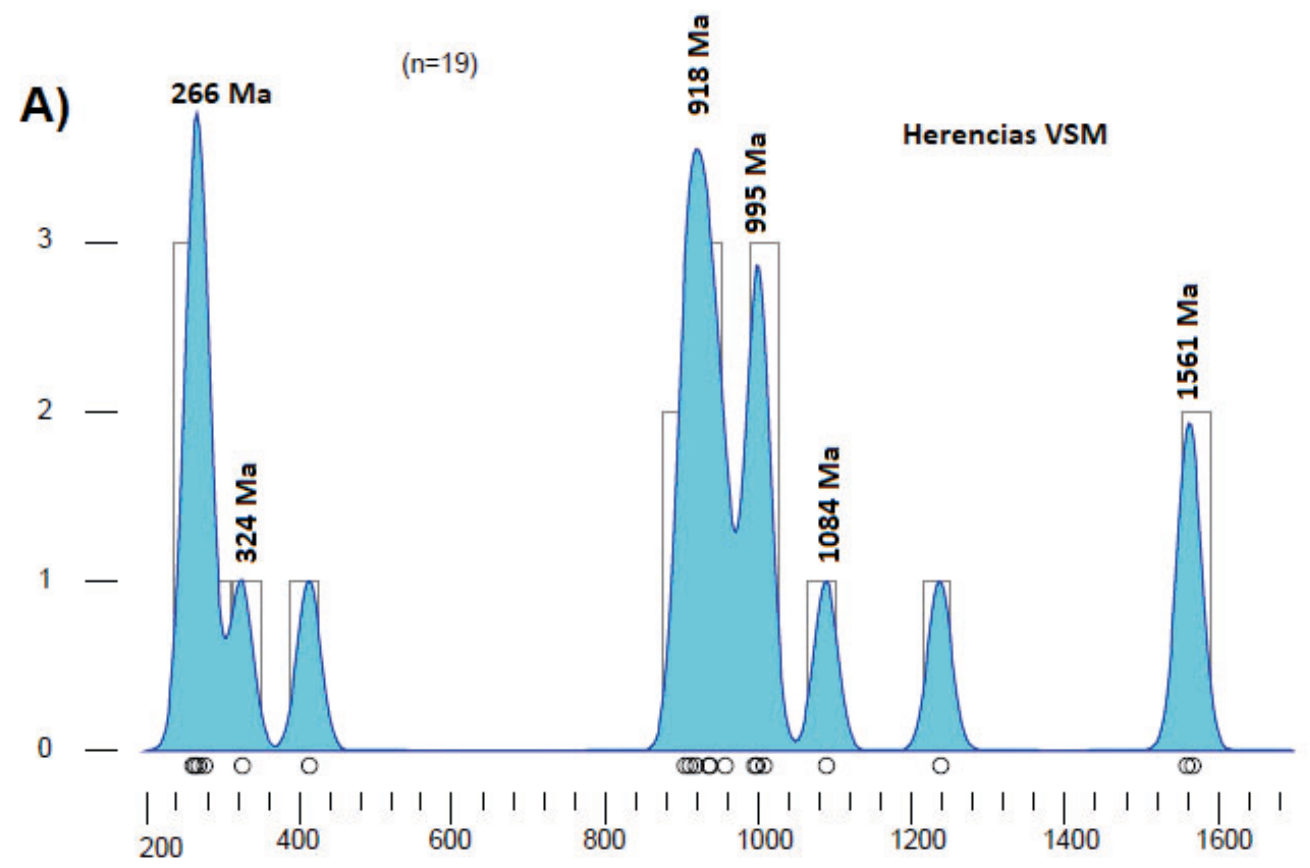

B)

$12-$ $(n=29)$

Herencias SNSM

$9-$

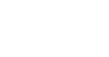

$6-$
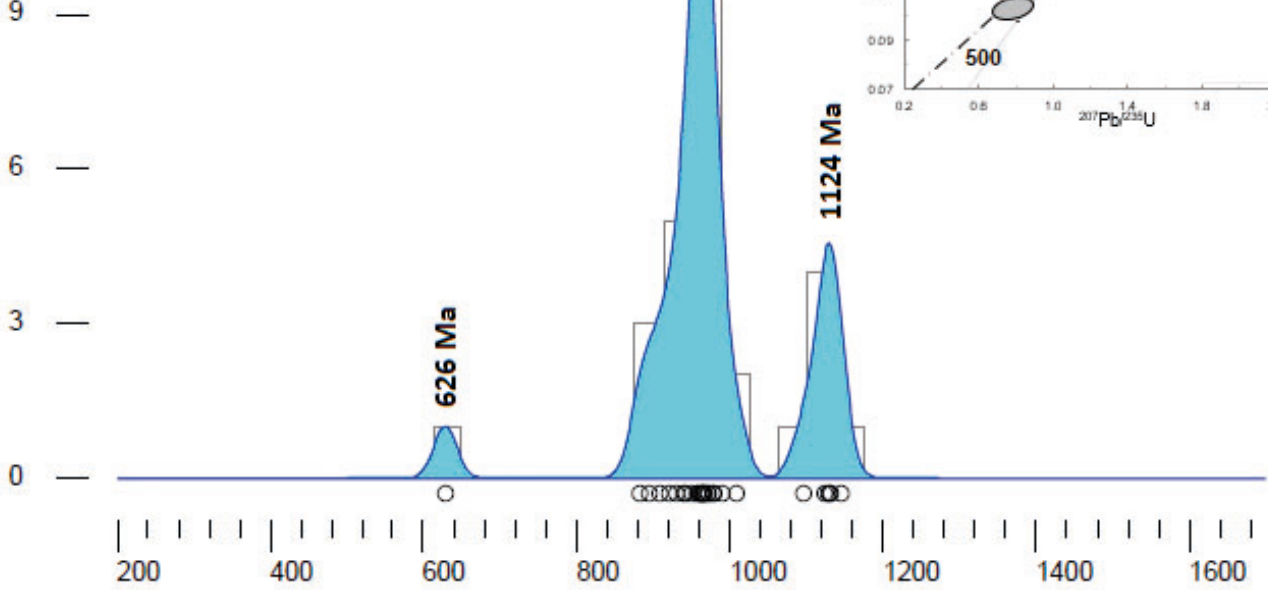

Figura 11. Diagramas de estimación de densidad de Kernel a partir de circones heredados en plutones de edad Jurásico Inferior a Medio A. VSM. B. SNSM. C. Diagrama de concordia de los circones heredados de la SNSM. 


\section{Características del plutonismo del AMSM en Colombia}

La variación composicional del plutonismo Jurásico Inferior a Medio en sentido este - oeste fue reconocida en trabajos anteriores de cartografía regional del VSM (Jaramillo y Escovar, 1980; Núñez et al., 1996; Rodríguez et al., 2018) y la SNSM (Tschanz et al., 1969b).

En el VSM el Cinturón Occidental está constituido por cuarzomonzonitas, monzonitas cuarzomonzodioritas, dioritas y ocasionalmente charnoquitas con presencia de hornblenda, biotita, clinopiroxeno y ortopiroxeno. Los plutones tienen edades de cristalización entre 195 y 179 Ma (Rodríguez et al., 2020). El Cinturón Oriental está constituido por granodioritas, monzogranitos y sienogranitos con biotita, con edades de cristalización entre 173 a 169 Ma y edades de antecristales entre 182 y 179 Ma (Rodríguez et al., 2020). Este segmento presenta variación composicional espacial y cambios en las edades de cristalización en sentido oeste-este, con un registro magmático menor a 173 Ma únicamente en los plutones orientales.

El Cinturón Occidental en la SNSM está constituido por tonalitas, granodioritas y monzogranitos, con edades de cristalización entre 188 y 172 Ma $(n=12)$, con picos máximos a ca. 186 y 176 Ma. El Cinturón Oriental está constituido por monzogranitos a sienogranitos de edades entre 192 y $164 \mathrm{Ma}(\mathrm{n}=28)$, con picos a ca. 186, 179-176 y 172-170 Ma. El plutonismo ocurrió en ambos cinturones entre ca. 193 y 164 Ma, pero a partir de 172 Ma, el registro magmático solamente se encuentra en las rocas del Cinturón Oriental, en plutones de la SNSM y el VSM. En la SSL los cuerpos batolíticos están conformados por tonalitas, granodioritas, monzogranitos. Las edades de cristalización varían entre ca. 192 y $173 \mathrm{Ma}$, con picos de cristalización a ca. 192, 185 y $182 \mathrm{Ma}$, similar a la edad de cristalización del Cinturón Occidental de la SNSM y el VSM.

Las diferentes edades de los plutones del AMSM sugieren que estos cuerpos son el resultado de varios pulsos magmáticos generados en el mismo arco, los cuales se reconocen a partir del análisis estadístico de las edades (diagramas de densidad de probabilidad generados a partir de la Tabla TS3), correspondiendo a cuatro eventos principales de cristalización, que sugieren la migración espacial del magmatismo en sentido oeste-este, presentando los plutones rejuvenecimiento y cambios composicionales en los diferentes segmentos del arco.
En los diagramas tipo Harker la tendencia es continua, y sugiere la evolución magmática del arco en el tiempo, con cambios composicionales en dirección oeste-este como norte-sur: la primera cristalización en los segmentos SNSM, SSL y VSM, ocurrió alrededor de $195 \mathrm{Ma}$, las rocas son de composición intermedia a básica (monzodioritas, cuarzomonzodioritas, tonalitas); variando hacia el este las edades de cristalización alrededor de 170 $\mathrm{Ma}$, junto con un cambio composicional, que al final del arco formó plutones monzograníticos a sienograníticos. En sentido norte-sur, las edades de cristalización en los segmentos dispersados del arco son equivalentes; hay empobrecimiento de $\mathrm{SiO}_{2}$ en el Cinturón Occidental, siendo en general más pobres en $\mathrm{SiO}_{2}$ y más ricos en $\mathrm{K}_{2} \mathrm{O}$ los plutones del VSM que los de la SNSM, y los de la SSL tienen contenidos de $\mathrm{SiO}_{2}$ que varían entre $55 \%$ y $70 \%$ y el contenido de $\mathrm{K}_{2} \mathrm{O}$ está disperso; probablemente estas diferencias composicionales se deben a cambios en el ángulo de subducción de la placa y la profundidad de generación del magma influenciado por el espesor cortical como se mostrará más adelante. El magmatismo en el VSM probablemente fue generado a mayor profundidad, la cual disminuyó progresivamente hacia el norte del arco en la SNSM; y en sentido oeste-este el magmatismo fue progresivamente más maduro.

Los plutones del AMSM son calcoalcalinos a ligeramente alcalino-cálcicos, altos en $\mathrm{K}$, varían de metaluminosos a peraluminosos, con anomalías negativas de Nb, Ti y P en el diagrama multielemental normalizado al NMORB (Pearce, 1996). Esto sugiere la entrada de material reciclado desde la corteza a través de procesos de subducción. Los valores de las relaciones $(\mathrm{La} / \mathrm{Yb})_{\mathrm{N}}$ vs $\mathrm{Sr} / \mathrm{Y}$ colocan estos magmas en el campo de arcos continentales, con la relación $(\mathrm{La} /$ $\mathrm{Yb})_{\mathrm{N}}$ ligeramente mayor y $\mathrm{Th} / \mathrm{Yb}$ ligeramente menor en los plutones del Cinturón Oriental.

Las relaciones $\mathrm{La} / \mathrm{Yb}$ y $\mathrm{Sr} / \mathrm{Y}$ pueden ser usadas como estimadores del grosor de la corteza en el momento de cristalización de los plutones (Profeta et al., 2015). Para la aplicación y estimación del grosor cortical no se consideraron las muestras con contenidos de $\mathrm{MgO}>4$ wt \% y de $\mathrm{SiO}_{2}<55$ y $>68$ wt $\%$, con el fin de descartar rocas derivadas de fuente mantélicas y rocas con alto contenido de sílice. Las estimaciones fueron calculadas a partir de la ecuación $D m=21,277 * \operatorname{Ln}\left(1,0204 * \frac{L a}{Y b n}\right)$, con $D m=$ espesor cortical (Profeta et al., 2015) y valores de normalización de Sun y McDonough (1989) (Tabla TS4). En la SNSM arrojaron espesores entre 33,8 - 40,6 
km para los plutones del Cinturón Occidental y entre 40,9 - 62,5 km para las rocas del Cinturón Oriental; en la SSL arrojaron espesores corticales entre $24 \mathrm{y}$ $63 \mathrm{~km}$, y en el VSM, el Cinturón Occidental arrojó espesores entre 34 - $60 \mathrm{~km}$ y el Cinturón Oriental entre $36-66 \mathrm{~km}$. El rango obtenido en los tres segmentos sugiere que la corteza donde se emplazó el arco en la SNSM aumentó de grosor de oeste a este, en la SSL el grosor es variable, en parte podría deberse a que no estén separados los cinturones, siendo el límite inferior $10 \mathrm{~km}$ menos grueso que el del VSM y presenta un grosor similar al grosos mayor del VSM. En el VSM el espesor de la corteza permanece constante de oeste a este, situación que seguramente influenció la inclinación de la placa subducente y generó el cambio composicional que registra el AMSM de sur a norte.

El contenido de Ti en la estructura del circón se usa para estimar la temperatura del magma en el momento de la cristalización del circón (Watson et al., 2006; Ferry y Watson, 2007; Siégel et al., 2018); y se calcula según la fórmula: $\mathrm{T}_{\text {Zirc(Ti) }}\left({ }^{\circ} \mathrm{C}\right)=5080 /\left(6,01 \log \left(\mathrm{Ti}_{\text {Zircon }}\right.\right.$; ppm) $\log \left(\mathrm{a}_{\text {ZircTi }}\right)-273$ (Ferry y Watson, 2007). Para la estimación de la temperatura de cristalización se tomaron los resultados de elementos traza en circón de 19 dataciones (Tabla TS5), de las cuales 17 corresponden a rocas de plutones del Cinturón Occidental $(n=243$ circones) y Oriental ( $\mathrm{n}=115$ circones) del VSM, y dos a plutones del Cinturón Oriental de la SNSM ( $\mathrm{n}=42$ circones). Se eliminaron los resultados químicos de circones heredados, circones eliminados en la determinación de la edad promedio ponderada de la roca y circones con valores de $\mathrm{Ti}>50 \mathrm{ppm}$ y $\mathrm{La}>1 \mathrm{de}$ acuerdo a las recomendaciones de Ferry y Watson (2007), cuyo valor alto puede obedecer a inclusiones al interior del cristal o a enriquecimiento en fracturas.

Las $\mathrm{T}_{\text {zircti }}$ de los plutones Jurásicos se comparan contra la edad $\left({ }^{206} \mathrm{~Pb} /{ }^{238} \mathrm{U}\right)$ de cada circón (Figura 12A, Tabla TS6). En el VSM, los circones del Cinturón Occidental presentan edades de cristalización más antiguas (entre 180 y $200 \mathrm{Ma}$ ) que los circones de plutones del Cinturón Oriental (entre 165 y 180 Ma) (Figura 12A). La $\mathrm{T}_{\text {zircTi }}$ para el conjunto de plutones del Cinturón
Occidental tiene un pico de cristalización a $860^{\circ} \mathrm{C}$, con un rango de temperaturas entre $660^{\circ} \mathrm{C}$ y $950^{\circ} \mathrm{C}$. Los plutones del Cinturón Oriental tienen $\mathrm{T}_{\text {zircTi }}$ con picos a $714^{\circ} \mathrm{C}, 807^{\circ} \mathrm{C}$ y $854^{\circ} \mathrm{C}$ y un rango de $\mathrm{T}_{\text {zircTi }}$ entre $600^{\circ} \mathrm{C}$ y $950^{\circ} \mathrm{C}$ (Figura 12B). La dispersión de $\mathrm{T}_{\text {zircTi }}$ del Cinturón Oriental se debe a diferentes temperaturas de cristalización del circón al interior de cada plutón y a diferencias de temperatura de cristalización en los diferentes plutones, resultado que es observado cuando se determina la temperatura de cristalización de cada muestra de manera individual. La edad de los circones de las dos muestras de plutones del Cinturón Oriental del SNSM tienen una variación de la edad entre 160 Ma y $185 \mathrm{Ma}$, pudiendo corresponder los circones con edad más viejas a antecristales; la $\mathrm{T}_{\text {zircTi }}$ presenta un pico de frecuencia de cristalización de $\sim 740^{\circ} \mathrm{C}$, con una distribución gaussiana, en un rango de $\mathrm{T}_{\text {zircti }}$ entre 700 y $780^{\circ} \mathrm{C}$, que corresponden a temperaturas más bajas de cristalización de estos plutones con relación a los del VSM (Figura 12B).

Los patrones de REE en circón de los plutones del Cinturón Occidental y Oriental del AMSM tienen anomalías positivas de Ce y negativa de Eu (Rodríguez et al., 2018, 2019b), con relación Eu/Eu* del Cinturón Oriental más alta que los del Cinturón Occidental (Tabla TS6), sugiriendo que son más hidratados y potencialmente fértiles para mineralizaciones de $\mathrm{Cu}$ (Figura 13A). Este resultado es concordante con la mineralogía de los plutones de los dos cinturones: el occidental tiene minerales menos hidratados como hornblenda y anhidros como orto y clinopiroxeno y el oriental tiene minerales hidratados como biotita y hornblenda.

La relación $\mathrm{Ce} / \sqrt{ }(\mathrm{U}$ x Ti) en el circón, fue propuesta como una aproximación al estado de oxidación del magma (Loucks et al., 2020), los resultados indican que los magmas del Cinturón Oriental son más oxidados de acuerdo al diagrama de $\mathrm{Eu} / \mathrm{Eu}^{*}$ vs $\mathrm{Ce} / \sqrt{ }(\mathrm{U} \times \mathrm{Ti})$ en el circón, propuesto por Lu et al. (2018) (Figura 13B), y sugieren que son potencialmente más fértiles. 


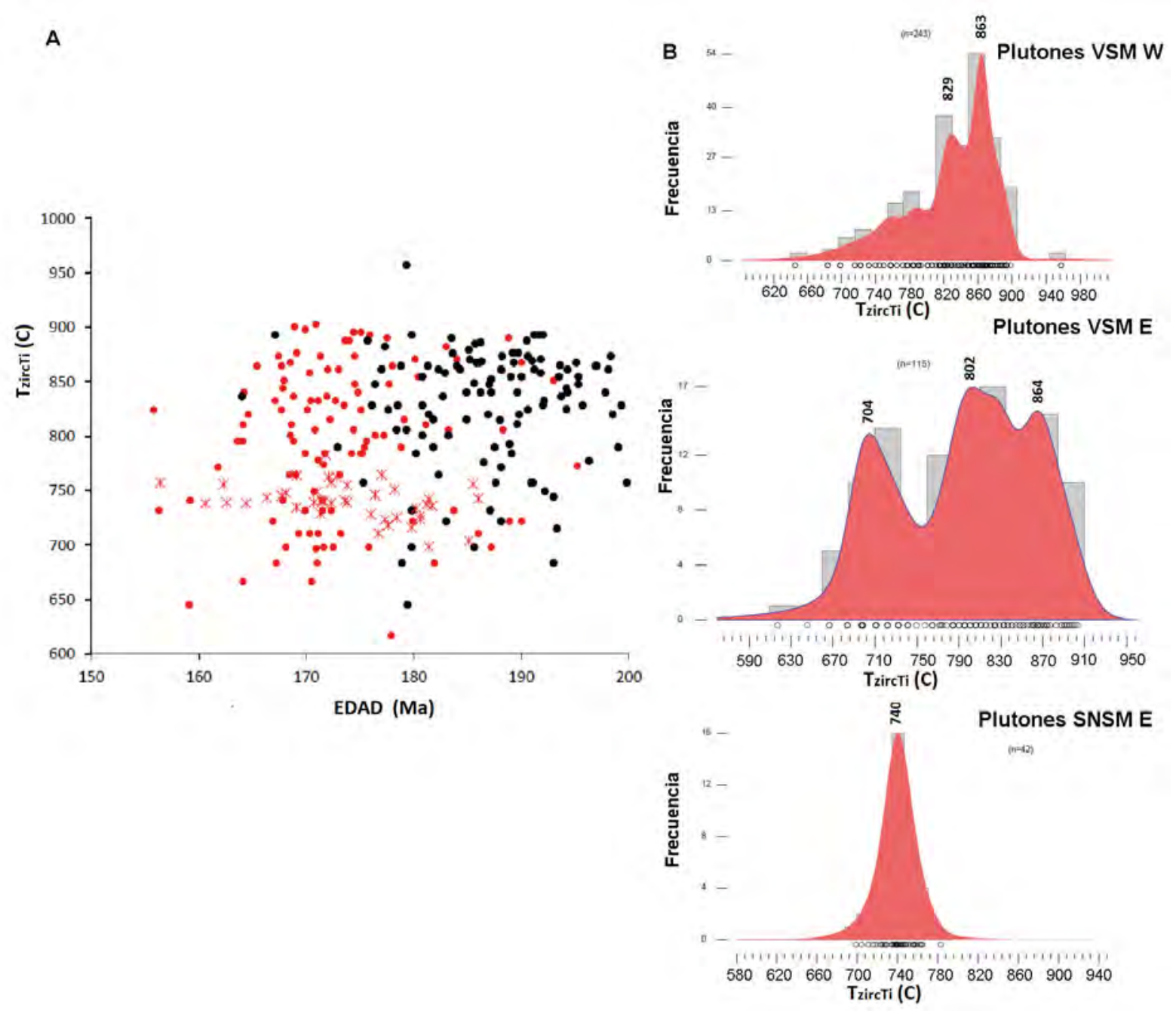

Figura 12. Diagramas de química del circón para muestras de plutones Jurásicos del VSM y la SNSM. A. Diagrama de Edad vs Temperatura de cristalización del circón $\left(\mathrm{T}_{\text {zircTi }}\right)$. B. Diagramas de estimación de densidad de Kernel para la temperatura de cristalización de circon $\left(\mathrm{T}_{\text {zircTi }}\right)$. 

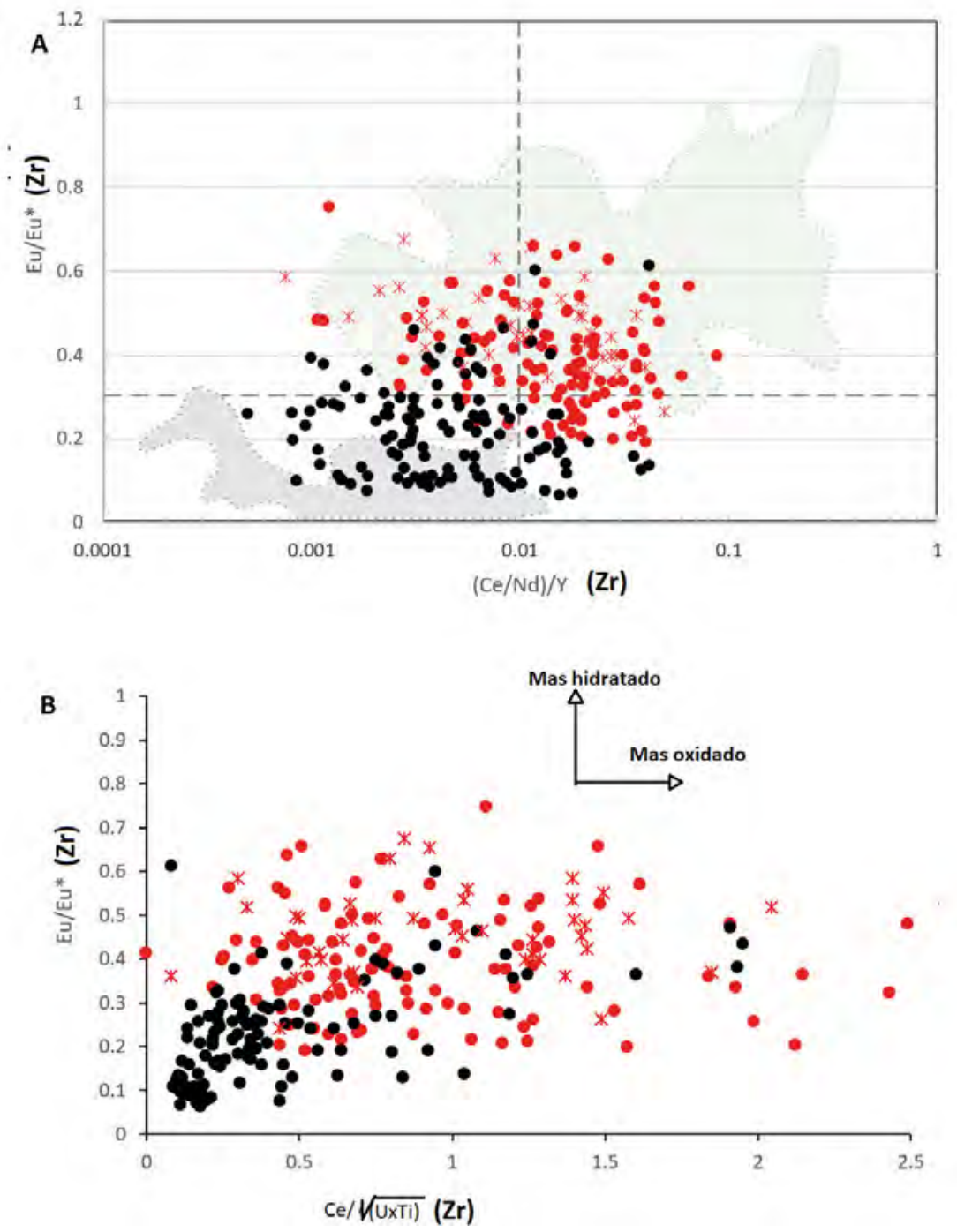

Figura 13. Diagramas de fertilidad de magmas para mineralizaciones de $\mathrm{Cu}$ a partir de la química de circones de muestras de plutones Jurásicos del VSM y la SNSM. A. Eu/Eu* vs $(\mathrm{Ce} / \mathrm{Nd}) / \mathrm{Y}(\mathrm{Lu}$ et al., 2016), con campos de suites fértiles para $\mathrm{Cu}$ (en verde claro) e infértiles (en gris). Valores de normalización usados para calcular Eu/Eu*: de Sun y McDonough (1989). B) Diagrama de $\mathrm{Eu} / \mathrm{Eu}^{*}$ vs $\mathrm{Ce} / \sqrt{ }(\mathrm{U}$ x Ti) en circón (Lu et al., 2018). El aumento en el grado de hidratación y oxidación de los magmas es indicado por las flechas. Valores normalizados con relación al condrito según Sun y McDonough (1989).

\section{Geoquímica isotópica}

Los datos isotópicos fueron compilados de los trabajos de Ríos-Blandón (2016) para los plutones de la AG, Leal-Mejía (2011) para los plutones de la SSL y Quandt et al. (2018) para los plutones de la SNSM (Tabla TS6).

Las razones ${ }^{87} \mathrm{Sr} /{ }^{86} \mathrm{Sr}$ y $\varepsilon_{\mathrm{d}}$ (180 Ma) (Tabla TS6), resultados compilados de los trabajos de LealMejía (2011), Ríos-Blandón (2016) y Quandt et al. (2018). En el diagrama de la Figura 14A, las muestras de los cinturones Occidental y Oriental, presentan enriquecimiento en ${ }^{87} \mathrm{Sr} /{ }^{86} \mathrm{Sr}$ (resultado de contaminación cortical) y bajo $\mathrm{ENd}$ comparado con el Bulk Silicate Earth (BSE), sugiriendo que son parte de una misma suite magmática con aporte de fuentes mantélicas. Sin embargo, los plutones del Cinturón Oriental presentan un menor enriquecimiento cortical $\left({ }^{87} \mathrm{Sr} /{ }^{86} \mathrm{Sr}=0,705\right)$ respecto a los plutones del Cinturón Occidental $\left({ }^{87} \mathrm{Sr} /{ }^{86} \mathrm{Sr}=0,707\right)$. Las muestras JRQ-26102L y JRQ-26-104L presentan un comportamiento anómalo al resto de las muestras, con valores más bajos de ${ }^{87} \mathrm{Sr} /{ }^{86} \mathrm{Sr}$ como se observa en la Figura 14B.

$\mathrm{La}$ composición isotópica de $\mathrm{Pb}$ de los plutones 
de los cinturones Oriental y Occidental $(\mathrm{n}=15)$ es caracterizada por ${ }^{206} \mathrm{~Pb} /{ }^{204} \mathrm{~Pb}$ entre $18,14-18,85$ y un dato con valores de 21,55 y ${ }^{207} \mathrm{~Pb} /{ }^{204} \mathrm{~Pb}$ entre 15,57 15,76 correspondiente a la SSL. Las muestras caen en el campo de los ambientes orogénicos, Figura 14B (curvas de evolución Plumbotectónicas de Zartman y Doe, 1981). Chiaradia et al. (2004) propone en Ecuador que las variaciones isotópicas de $\mathrm{Pb}$ son atribuidas a mezcla de una fuente tipo MORB y el basamento de los terrenos Cajamarca-Valdivia. Se propone que estas variaciones isotópicas son la mezcla de una fuente tipo MORB, el basamento del Orogéno Putumayo (Ibáñez-Mejía et al., 2011, 2015) y el Arco Pérmico descrito por Rodríguez et al. (2019a), apoyados en las herencias de circones.
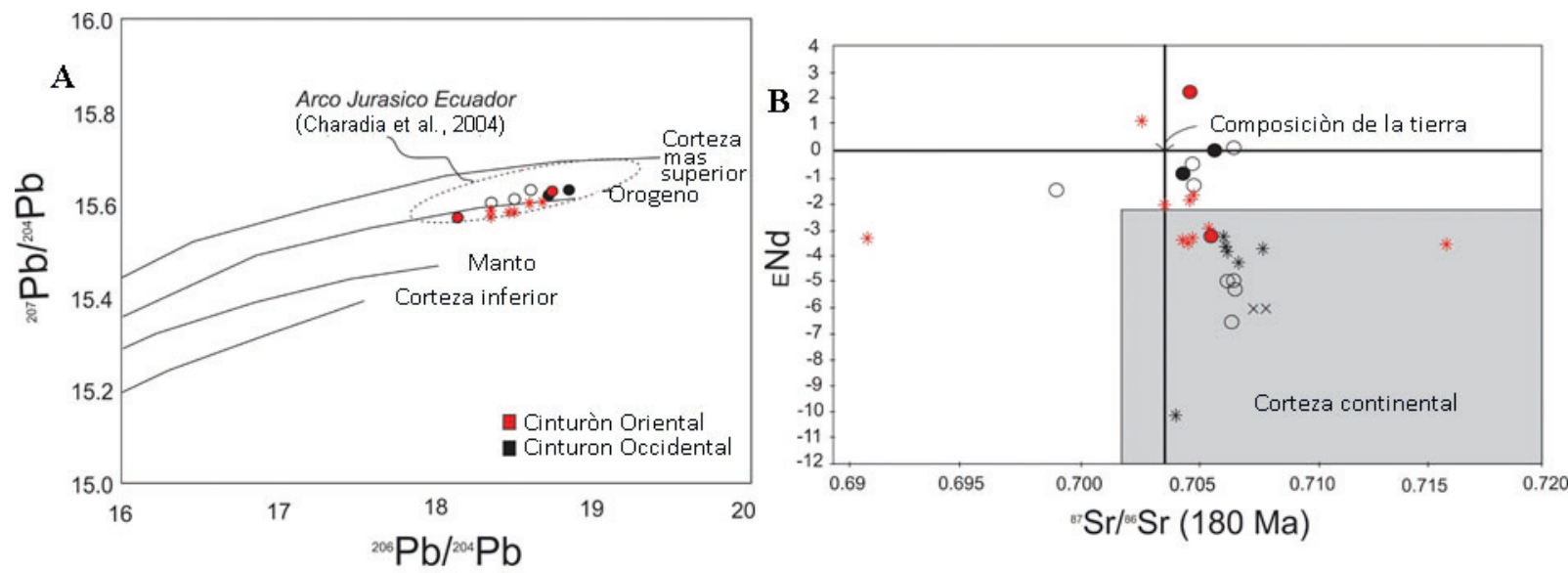

Figura 14. Composición isotópica para muestras de los plutones jurásicos del AMSM: A. Diagrama ${ }^{206} \mathrm{~Pb} /{ }^{204} \mathrm{~Pb} v{ }^{207} \mathrm{~Pb} /{ }^{204} \mathrm{~Pb}$ (Uranogenico) con curvas de evolución de Pb según el modelo Plumbotectonics (Zartman y Doe, 1981), B. Diagrama ENd vs ${ }^{87} \mathrm{Sr} /{ }^{86} \mathrm{Sr}$ corregido a $180 \mathrm{Ma}$. Símbolos de acuerdo con la leyenda de la Figura 3. Datos compilados de Leal-Mejía (2011) y Quandt et al. (2018).

\section{Modelos propuestos}

Los primeros trabajos del magmatismo Jurásico del norte de los Andes sugieren un modelo de arco genéticamente relacionado con la placa oceánica de Farallón (Núñez, 1978; Jaramillo y Escovar, 1980; Bayona et al., 1994; Toussaint, 1995), idea que fue demostrada posteriormente a partir de datos de geoquímica de roca total (Álvarez, 1983; Bustamante et al., 2010; Leal-Mejía, 2011; Spikings et al., 2015; Villagómez et al, 2015; Zapata et al., 2016; QuicenoColorado et al., 2016; Zuluaga et al., 2017; Rodríguez et al, 2015f, 2018, 2020; Quandt et al., 2018; Zuluaga y López, 2019; Leal-Mejía et al., 2019). Un segundo modelo surgió para explicar el magmatismo a partir de la apertura de un rift intracontinental (Pindell y Dewey, 1982; Ross y Scotese, 1988; Cochrane et al., 2014; Cediel et al., 2003), el cual perdió validez con los nuevos datos.

La migración del magmatismo fue planteada desde los trabajos de cartografía, donde se reconocieron cambios en la composición de los plutones en sentido oeste-este (Tschanz et al., 1969a, 1969b; Jaramillo y
Escovar, 1980; Núñez et al., 1996), quienes por falta de datos de geoquímica y geocronología involucraron plutones de otros arcos. Trabajos más recientes han planteado un modelo de subducción oblicua entre la placa oceánica de Farallón y el NW de Suramérica, para explicar los cambios composicionales y de edades (Bayona et al., 2010; Bustamante et al., 2016; Quandt et al., 2018), también se ha propuesto el modelo de un arco continental y de trasarco que fue dispersado en segmentos a lo largo de la margen Suramericana y que comprende rocas jurásicas del Valle Superior del Magdalena, la Cordillera Central de Colombia, la Serranía de San Lucas y la Sierra Nevada de Santa Marta (Bayona et al., 2010; Villagómez et al., 2015; Rodríguez et al., 2020). Leal-Mejía et al. (2019) plantean para el magmatismo Jurásico la migración del magmatismo en sentido este-oeste, modelo que inicia con el magmatismo en un rift temprano que corresponde al magmatismo del Macizo de Santander, seguido de una subducción continua en dirección este, a partir de la subducción de la placa Farallón.

En este trabajo se plantea un modelo de subducción con erosión de la cuña a lo largo de la Paleomargen 
Suramericana, ortogonal a la margen, con rejuvenecimiento y migración en sentido oesteeste, el cual formó los primeros plutones durante el Carbonífero (e.d. Stock del Carmen) y tuvo el mayor episodio de producción magmática durante el Pérmico con la cristalización de los granitos de Ortega y La Plata en el VSM, el Neis de Nechí y la Diorita de Remedios en la SSL y el Ortoneis de El Encanto en la SNSM, finalizando el magmatismo a comienzos del Triásico, este magmatismo corresponde al Arco Pérmico descrito por Rodríguez et al. (2019a) en el borde más occidental de la margen continental de Gondwana (Figura 15A). Finalizado el magmatismo del Arco Pérmico, inició a principios del Triásico hasta el Jurásico un periodo de distensión con erosión de la margen, transgresión marina y sedimentación en el borde occidental de Gondwana, representado por unidades como las formaciones Luisa y Payandé en el VSM, Morrocoyal en la SSL, Los Indios en la SNSM (Figura 15B).

A principios del Jurásico ( 195 Ma), se reactivó la subducción de la placa Pacifica y el inicio del AMSM a lo largo de la Paleomargen Suramericana (NW de Gondwana), se formaron los primeros plutones (Cinturón Occidental) y se formó junto al plutonismo vulcanismo de arco: Riodacitas del Cerro La Teta e Ipapure en la AG, las vulcanitas de la Formación La Quinta en la Serranía de Perijá, el Complejo Volcánico de la Sierra Nevada en la SNSM, las formaciones Noreán en la SSL y Saldaña en el VSM, tanto el vulcanismo como el plutonismo se emplazó en el borde oriental del Arco Pérmico y en el basamento continental. El magmatismo del AMSM continúo por \%30 Ma, migrando hacia el este y formando plutones más diferenciados (Cinturón Oriental) (Figura 15C). La subducción y el AMSM, finalizaron en el Jurásico Medio, aproximadamente a 164 Ma, coincidiendo con el inicio de la colisión de la margen occidental de Gondwana con el Terreno Tahamí (Blanco-Quintero et al., 2014; Rodríguez et al., 2017b, 2020) y el colapso de la zona de subducción con el estrangulamiento de la placa subducida, formando los últimos plutones del arco que corresponden a pórfidos andesíticos de afinidad alcalina (Rodríguez, 2018), generando en la zona de colisión deformación y metamorfismo orogénico de edad Jurásica Superior ( 158 a 150 Ma) (Orógeno Tierradentro), afectando principalmente rocas sedimentarias de la fosa y el Terreno Tahamí. Un salto de la zona de subducción generó una nueva subducción al occidente del Terreno Tahamí (Figura 15D), la cual sería la causante de formar un nuevo arco con la intrusión sin y postectónica del Batolito de Ibagué y el Batolito de Segovia en una posición más occidental al AMSM, a lo largo de la sutura entre los terrenos Chibcha y Tahamí y dentro del Orógeno Tirerradentro, intruyendo ambas márgenes (Terreno Tahamí, Orógeno Tierradentro y Arco Pérmico) (Figura 15D).

La cristalización del plutonismo del AMSM inició alrededor de ca. $193 \mathrm{Ma}$, en los segmentos SNSM, SSL, VSM y AG, presenta cuatro eventos de cristalización, y finalizó entre 168 y 164 Ma en el Cinturón Oriental, presente en los segmentos VSM y SNSM. El arco tiene variación composicional en sentido oeste-este, documentada por las observaciones de campo, los resultados de los análisis petrográficos, la química de roca total, la química del circón y la química isotópica. Además, tiene variaciones composicionales en sentido norte-sur con una disminución en el contenido de $\mathrm{SiO}_{2}$ en los plutones del Cinturón Occidental del VSM con relación a los de la SNSM. Los plutones tienden a ser más jóvenes en sentido oeste-este, lo que sugiere que la subducción fue en esta misma dirección y la variación composicional hacia plutones mas diferenciados podría estar relacionada con la mayor profundidad de generación de los fundidos por encima de la placa subducente; o como sugieren Rodríguez et al. (2018) debido a la erosión del prisma acrecionario se produjo la migración del arco y de la fosa, al incremento de la fusión parcial de roca fuente y corteza continental por mayor entrada de agua al sistema que generó rocas graníticas más hidratadas, de acuerdo a la química de roca total y del circón que muestran los plutones orientales más hidratados y oxidados que los plutones occidentales.

El AMSM tiene el mismo rango de edades de cristalización en sentido norte-sur para los diferentes segmentos dispersados a lo largo de la paleomargen continental, esto sugiere una probable subducción perpendicular a la margen en esta parte de los Andes de Colombia. Las variaciones composicionales en sentido norte-sur podrían ser explicadas por cambios en el ángulo de subducción de la placa del Pacifico por debajo de la corteza continental, debido a diferencias de espesor de la corteza: en el VSM el espesor de la corteza continental fue calculado entre 34 y $66 \mathrm{~km}$, en la SNSM la corteza muestra engrosamiento hacia el este, variando de 33 a $40 \mathrm{~km}$ al oeste a 40 a $62 \mathrm{~km}$ al este. Los valores calculados para la temperatura de cristalización del circón $\left(\mathrm{T}_{\text {zircTi }}\right)$ parecen disminuir en sentido oeste-este, siendo la mayor frecuencia para la temperatura de cristalización de circón de los plutones del Cinturón Occidental del VSM de $\sim 860^{\circ} \mathrm{C}$, acorde 
con la presencia de orto y clinopiroxeno en las rocas, en tanto que en los plutones orientales se observan tres picos a $714^{\circ} \mathrm{C}, 807^{\circ} \mathrm{C}$ y $854^{\circ} \mathrm{C}$, una mayor hidratación y oxidación de los magmas, con presencia de biotita como mineral máfico dominante. Por otra parte el
Cinturón Oriental de la SNSM presenta temperaturas de cristalización del circón $\left(\mathrm{T}_{\text {zircTi }}\right.$ ) con un pico a $\sim 740^{\circ} \mathrm{C}$, más baja que la $\mathrm{T}_{\text {zircTi }}$ del VSM, sugiriendo un posible aumento de la temperatura de cristalización de los plutones en el AMSM en sentido norte-sur.
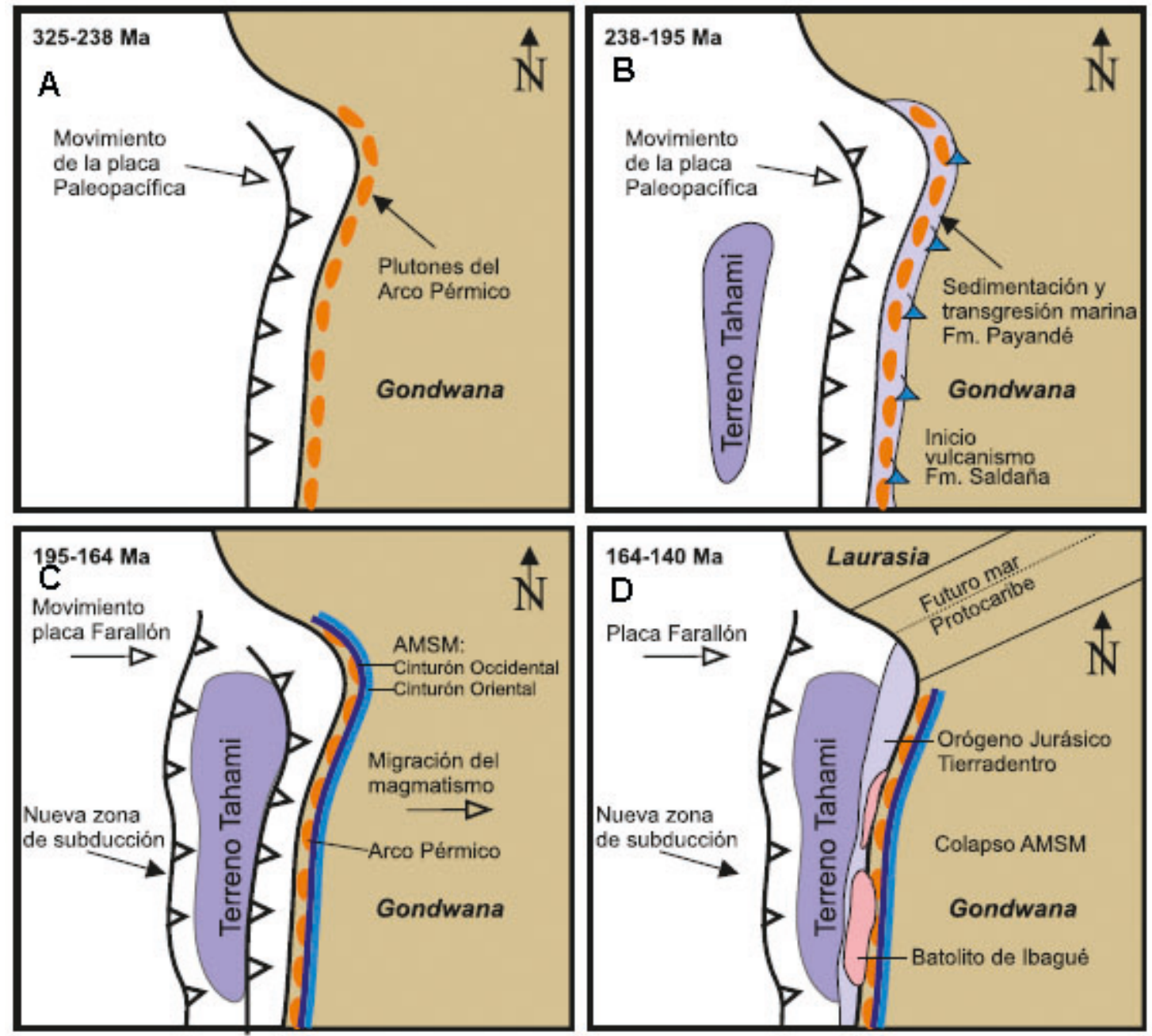

Figura 15. Modelo propuesto para la evolución tectónica del noroccidente de Gondwana y del AMSM desde el Carbonífero hasta el Cretáceo. A. Evolución de la Paleomargen entre 325b y 238 Ma. B. Evolución de la Paleomargen entre 238 y 195 Ma. C. Evolución de la Paleomargen entre 195 y 164 Ma. D. Evolución de la Paleomargen entre 164 y 140 Ma.

\section{Conclusiones}

Los cambios composicionales y las diferencias observadas a partir de los datos compilados y nuevos, permite confirmar la presencia de dos cinturones y la evolución espacio-temporal del AMSM.

El AMSM se emplazó en un basamento constituido por rocas metamórficas de edad Neo-proterozoica (Orógeno Putumayo), rocas sedimentarias de edad
Paleozoico y plutones del Arco Pérmico, que en conjunto corresponden al Terreno Chibcha (Rodríguez et al., 2019a; Restrepo y Toussaint, 2020). El AMSM fue dispersado posteriormente a lo largo de la margen noroccidental de Suramérica y se presenta en Colombia en segmentos separados a lo largo de la paleomargen de Suramérica (Bayona et al., 2010; Villagómez et al., 2015), que son de sur a norte los segmentos VSM, la SSL, la SNSM y la AG. 
Los plutones del AMSM cristalizaron entre ca. $193 \mathrm{Ma}$ y 164 Ma. En ese intervalo de tiempo se reconocen cuatro periodos de cristalización que son comunes a los plutones que se presentan en los diferentes segmentos dispersados ( 192 Ma, $188-186 \mathrm{Ma}, \sim 182-178$ Ма у 172-168 Ma). El AMSM tiene migración general de las edades del plutonismo en sentido oeste-este, con rejuvenecimiento de los plutones, acompañado por cambios composicionales que permiten agruparlos en dos cinturones: los plutones occidentales son de composición básica a intermedia (gabros, monzogabros, dioritas, monzodioritas, monzonitas, cuarzomonzonitas, tonalitas y granodioritas) y los plutones orientales de composición intermedia a ácida (monzogranitos y sienogranitos). El AMSM presenta cambios composicionales en sentido norte-sur, con disminución de contenidos de cuarzo de los plutones que componen el Cinturón Occidental.

El AMSM varía de metaluminoso a peraluminosos en sentido oeste-este; corresponde a granitos Tipo $\mathrm{I}$, calcoalcalinos altos en $\mathrm{K}$, con algunas muestras en el campo de los intrusivos alcalino cálcicos, con anomalía negativa de $\mathrm{Nb}$, Ti y $\mathrm{P}$, y anomalía positiva y valores altos de $\mathrm{Cs}, \mathrm{Rb}, \mathrm{Ba}$, Th, $\mathrm{K}$ y $\mathrm{Pb}$; con enriquecimiento en tierras raras livianas (LREE) y empobrecimiento progresivo hacia las tierras raras pesadas (HREE), formados en un ambiente de arco de margen continental.

La química de los circones sugiere mezcla de una fuente tipo MORB y la fusión de rocas corticales del Orógeno Putumayo, sedimentos Paleozoicos y plutones de edad Pérmica, soportado por las herencias de circones Meso-proterozoicos ( 1561 Ma, 1124 Ma), Neo-proterozoicos ( 995 Ma, $958 \mathrm{Ma}, \sim 918$ Ma), Pérmicos ( 266 Ma), y un solo dato a 1235, 411, 324 Ma y por los resultados isotópicos obtenidos por otros autores.

El plutonismo presenta empobrecimiento en $\mathrm{TiO}_{2}$, $\mathrm{Al}_{2} \mathrm{O}_{3}, \mathrm{MgO}, \mathrm{CaO}$, FeOt y $\mathrm{P}_{2} \mathrm{O}_{5}$ del AMSM en el tiempo y espacialmente en sentido oeste-este, aumento de $\mathrm{K}_{2} \mathrm{O}$ y $\mathrm{Na}_{2} \mathrm{O}$ con aumento de $\mathrm{SiO}_{2}$; mayor relación $\mathrm{La} / \mathrm{Yb}$ y aumento en la hidratación y oxidación del magma pasando de magmas infértiles a potencialmente fértiles en $\mathrm{Cu}$.

\section{Agradecimientos}

Agradecemos al Servicio Geológico Colombiano (SGC) por la financiación del proyecto. A los laboratorios de Petrografía y Química del SGC por la elaboración de las secciones delgadas y los análisis químicos de las muestras, respectivamente. Al Laboratorio de Geocronología del SGC por las dataciones radiométricas $\mathrm{U}-\mathrm{Pb}$ en circón. A los geólogos Gilberto Zapata, María Isabel Arango y José Gilberto Bermúdez por el apoyo en el muestreo de campo. A Hildebrando Leal por la revisión y comentarios que fueron importantes para mejorar el artículo. Queremos agradecer al revisor anónimo con sus observaciones positivas para que los autores nos esforzáramos en mejorar el texto.

\section{Referencias}

Álvarez, W. (1967). Geology of the Simarua and Carpintero areas, Guajira Peninsula, Colombia. $\mathrm{PhD}$ thesis. Princeton University, New Jersey, USA.

Álvarez, J. (1983). Geología de la Cordillera Central y el occidente colombiano y petroquímica de los intrusivos granitoides mesocenozoicos. Boletín Geológico, 26(2), 1-175.

Arango, M.I.; Rodríguez, G.; Bermúdez, J.G.; Zapata, G. (2015a). Catálogo de Unidades Litoestratigráficas de Colombia: Cuarzomonzonita de Anchique, Cordillera Central, Huila. Servicio Geológico Colombiano. 26p, Bogotá.

Arango, M.I.; Rodríguez, G.; Bermúdez, J.G.; Zapata, G. (2015b). Catálogo de Unidades Litoestratigráficas de Colombia: Monzodiorita de Las Minas, Cordillera Central, Departamento del Huila. Servicio Geológico Colombiano. 26p, Bogotá.

Arango, M.I.; Rodríguez, G.; Zapata, G.; Bermúdez, J.G. (2015c). Catálogo de Unidades Litoestratigráficas de Colombia: Cuarzolatita de Teruel, Cordillera Central, Departamento del Huila. Servicio Geológico Colombiano. 25p, Bogotá.

Arango, M.I.; Rodríguez, G.; Zapata, G.; Bermúdez, J.G. (2015d). Catálogo de Unidades Litoestratigráficas de Colombia: Monzogranito de Altamira, Cordilleras Oriental y Central, Huila. Servicio Geológico Colombiano. 32p, Bogotá. 
Arango, M.I.; Rodríguez G.; Zapata, G.; Bermúdez, J.G. (2015e). Catálogo de Unidades Litoestratigráficas de Colombia: Monzogranito de Mocoa, Cordillera Oriental, Departamentos Putumayo, Huila, Cauca y Nariño. Servicio Geológico Colombiano. 41p, Bogotá.

Bayona, G.; García, D.; Mora, G. (1994). La Formación Saldaña: producto de la actividad de estratovolcanes continentales en un dominio de retroarco. En: F. Etayo-Serna (ed.). Estudios Geológicos del Valle Superior del Magdalena (pp. 1-21). Universidad Nacional de Colombia.

Bayona, G.; Rapalini, A.; Costanzo-Alvarez, V. (2006). Paleomagnetism in Mesozoic rocks of the northern Andes and its implications in Mesozoic tectonics of northwestern South America. Earth, Planets and Space, 58(10), 1255-1272. https:// doi.org/10.1186/BF03352621

Bayona, G.; Jiménez, G.; Silva, C.; Cardona, A.; Montes, C.; Roncancio, J.; Cordani, U. (2010). Paleomagnetic data and K-Ar ages from Mesozoic units of the Santa Marta massif: A preliminary interpretation for block rotation and translations. Journal of South American Earth Sciences, 29(4), 817-831. https://doi.org/10.1016/j. jsames.2009.10.005

Bermúdez, J.G.; Arango, M.I.; Rodríguez, G.; Zapata, G. (2015). Catálogo de Unidades Litoestratigráficas de Colombia: Cuarzomonzonita de San Cayetano, Cordilleras Central y Oriental, Departamento del Tolima. Servicio Geológico Colombiano. 31 p, Bogotá.

Blanco-Quintero, I.F.; García-Casco, A.; Toro, L.M.; Moreno, M.; Ruiz, E.C.; Vinasco, C.J.; Cardona, A.; Lázaro, C.; Morata, D. (2014). Late Jurassic terrane collision in the northwestern margin of Gondwana (Cajamarca complex, eastern flank of the Central Cordillera, Colombia). International Geology Review, 56(15), 1852-1872. https://doi. org/10.1080/00206814.2014.963710

Bogotá, J.; Aluja, J. (1981). Geología de la Serranía de San Lucas. Geología Norandina, 4, 49-55.

Botero, G. (1940). Geología sobre el Ordovíciano de Antioquia. Revista Minería, 17(99), 8249-8256.
Bustamante, C.; Cardona, A.; Bayona, G.; Mora, A.; Valencia, V.; Gehrels, G.; Vervoort, J. (2010). $\mathrm{U}-\mathrm{Pb}$ LA-ICP-MS geochronology and regional correlation of Middle Jurassic intrusive rocks from the Garzon Massif, upper Magdalena valley and Central Cordillera, southern Colombia. Boletín de Geología, 32(2), 93-109.

Bustamante, C.; Archanjo, C.; Cardona, A.; Vervoort, J. (2016). Late Jurassic to Early Cretaceous plutonism in the Colombian Andes: a record of long-term arc maturity. GSA Bulletin, 128(11-12), 1762-1779. https://doi.org/10.1130/B31307.1

Cardona, A.; Valencia, V.; Garzón, A.; Montes, C.; Ojeda, G.; Ruiz, J.; Weber, M. (2010). Permian to Triassic I to S-type magmatic switch in the northeast Sierra Nevada de Santa Marta and adjacent regions, Colombian Caribbean: Tectonic setting and implications within Pangea paleogeography. Journal of South American Earth Sciences, 29(4), 772-283. https://doi. org/10.1016/j.jsames.2009.12.005

Carvajal, C.; Fúquen, J.A.; Gómez, L.A.; Núñez, A. (1983). Cartografía geológica y prospección geoquímica regional plancha 282-Chaparral. Memoria. INGEOMINAS, Bogotá.

Carvajal, C.; Fúquen, J.A.; Gómez, L.A. (1993). Geología de la Plancha 282-Chaparral. Escala 1:100.000. INGEOMINAS, Bogotá.

Cediel, F.; Mojica, J.; Macía, C. (1980). Definición estratigráfica del Triásico en Colombia, Suramérica - Formaciones Luisa, Payandé y Saldaña. Newsletters on Stratigraphy, 9(2), 73104. https://doi.org/10.1127/nos/9/1980/73

Cediel, F.; Mojica, J.; Macia, C. (1981). Las formaciones Luisa, Payandé, Saldaña sus columnas estratigráficas características. Geología Norandina, 3, 11-19.

Cediel, F.; Shaw, R.P.; Cáceres, C. (2003). Tectonic assembly of the Northern Andean Block. In: C. Bartolini; R.T. Buffler; J. Blickwede (eds.). The Circum-Gulf of Mexico and the Caribbean: Hydrocarbon habitats, basin formation, and plate tectonics (pp. 815-848). AAPG Memoir 79. 
Chiaradia, M.; Fontboté, L.; Paladines, A. (2004). Metal sources in mineral deposits and crustal rocks of Ecuador $\left(1^{\circ} \mathrm{N}-4^{\circ} \mathrm{S}\right)$ : A lead isotope synthesis. Economic Geology, 99(6), 1085-1106. https://doi.org/10.2113/econgeo.99.6.1085

Clavijo, J. (1995). Mapa Geológico de Colombia. Plancha 75 - Aguachica. Escala 1:100.000. Memoria explicativa. INGEOMINAS, Bucaramanga.

Cochrane, R (2013). U-Pb thermochronology, geochronology and geochemistry of NW South America: rift to drift transition, active margin dynamics and implications for the volume balance of continents. PhD thesis, University of Geneva, Geneva, Switzerland.

Cochrane, R.; Spikings, R.; Gerdes, A.; Winkler, W.; Ulianov, A.; Mora, A.; Chiaradia, M. (2014). Distinguishing between in-situ and accretionary growth of continents along active margins. Lithos, 202-203, 382-394. https://doi.org/10.1016/j. lithos.2014.05.031

Colmenares, F.; Mesa, A.; Roncancio, J.; Arciniegas, E.; Pedraza, P.; Cardona, A.; Romero, A.; Silva, C.; Alvarado, S.; Romero, O.; Vargas, A. (2007). Geológica map of the Sierra Nevada de Santa Marta, scale 1:200,000, INGEOMINAS-InvemarEcopetrol-ICP-Geosearch, Ltda., Bogotá.

Condie, K.C.; Kröner, A. (2013). The building blocks of continental crust: Evidence for a major change in the tectonic setting of continental growth at the end of the Archean. Gondwana Research, 23(2), 394-402. https://doi.org/10.1016/j.gr.2011.09.011

Cordani, U.G.; Cardona, A.; Jimenez, D.M.; Liu, D.; Nutman, A.P. (2005). Geochronology of Proterozoic basement inliers in the Colombian Andes: tectonic history of remnants of a fragmented Grenville belt. Geological Society, London, Special Publications, 246, 329-346. https://doi.org/10.1144/GSL.SP.2005.246.01.13

Cordani, U.G.; Fraga, L.M.; Reis, N.; Tassinari, C.C.G.; Brito-Neves, B.B. (2010). On the origin and tectonic significance of the intra-plate events of Grenvillian-type age in South America: a discussion. Journal of South American Earth Sciences, 29(1), 143-159. https://doi. org/10.1016/j.jsames.2009.07.002
Cossio, U.; Rodríguez, G.; Rodríguez, M. (1994). Geología de la Plancha 283-Purificación, Departamento del Tolima. Escala 1:100.000. Memoria explicativa. INGEOMINAS. Ibagué.

Cuadros, F.A. (2012). Caracterização geoquímica e geocronológica do embasamento mesoproterozóico da parte norte da serrania de San Lucas (Colômbia). Dissertação Mestrado, Universidade de Brasília, Brasília, Brasil.

Cuadros, F.A.; Botelho, N.F.; Ordóñez-Carmona, O.; Matteini, M. (2014). Mesoproterozoic crust in the San Lucas Range (Colombia): An insight into the crustal evolution of the northern Andes. Precambrian Research, 245, 186-206. https://doi.org/10.1016/j.precamres.2014.02.010

Escorce, E. (1977). Mineralización de tipo pórfido cuprífero-área de Mocoa, Putumayo. INGEOMINAS.

Feininger, T.; Barrero, D.; Castro, N. (1972). Geología de parte de los departamentos de Antioquia y Caldas (Sub-zona II-B). Boletín Geológico, 20(2), 1-173.

Ferreira, P.; Núñez, A.; Rodríguez, M. (1998). Geología de la Plancha 323 Neiva. Escala 1:100.000. INGEOMINAS, Bogotá.

Ferreira, P.; Núñez, A.; Rodríguez, M. (2002). Levantamiento geológico de la Plancha 323 Neiva. Escala 1:100.000. Memoria explicativa. INGEOMINAS, Bogotá.

Ferry, J.; Watson, E. (2007). New thermodynamic models and revised calibrations for the Ti-in-zircon and Zr-in-rutile thermometers. Contributions to Mineralogy and Petrology, 154(4), 429-437. https://doi.org/10.1007/S00410-007-0201-0

Frost, B.R.; Barnes, C.G.; Collins, W.J.; Arculus, R.J.; Ellis, D.J.; Frost, C.D. (2001). A geochemical classification for granitic rocks. Journal of Petrology, 42(11), 2033-2048. https://doi. org/10.1093/petrology/42.11.2033

Gansser, A. (1955). Contribución a la geología y petrografía de la Sierra Nevada de Santa Marta (Colombia, Suramérica) (Traductor Cediel, F.). Bucaramanga: Inventario Minero Nacional (Zona III). 
GEOTEC. (2003). Interpretación de sensores remotos en la Serranía de San Lucas. Bogotá.

Geyer, O.F. (1973). Das präkretazische Mesozoikum von Kolumbien. Geologisches Jahrbuch, 5, 1-156.

González, H.; Núñez, A. (2001). Catálogo de unidades litoestratigráficas de Colombia. Monzogranito de Mocoa. INGEOMINAS. 29p, Bogotá.

González, H.; Maya, M.; Camacho, J.; Cardona, O.D.; Vélez, W. (2015a). Elaboración de la cartografía geológica de un conjunto de planchas a escala 1:100.000 ubicadas en cuatro bloques del territorio nacional, identificados por el Servicio Geológico Colombiano. Plancha 74 - Guaranda. Servicio Geológico Colombiano.

González, H.; Maya, M.; García, J.F.; Gómez, J.P.; Palacio, A.F.; Vélez, W. (2015b). Elaboración de la cartografía geológica de un conjunto de planchas a escala 1:100.000 ubicadas en cuatro bloques del territorio nacional, identificados por el Servicio Geológico Colombiano. Plancha 95 Buenavista. Servicio Geológico Colombiano.

González, H.; Maya, M.; Tabares, L.F.; Palacio, A.F.; Gómez, J.P.; Montoya, A.; Vélez, W. (2015c). Elaboración de la cartografía geológica de un conjunto de planchas a escala 1:100.000 ubicadas en cuatro bloques del territorio nacional, identificados por el Servicio Geológico Colombiano. Plancha 107 - Cerro Azul. Servicio Geológico Colombiano.

González, H.; Maya, M.; Tabares, L.F.; Montoya, A.; Palacio, A.F.; Sánchez, C.; Barajas, A.; Vélez, W. (2015d). Elaboración de la cartografía geológica de un conjunto de planchas a escala 1:100.000 ubicadas en cuatro bloques del territorio nacional, identificados por el Servicio Geológico Colombiano. Plancha 118 - San Francisco. Servicio Geológico Colombiano.

Guerrero, B.; Támara, A. (1982). Petrografía de los intrusivos Triásico - Jurásicos y sus relaciones con la Formación Saldaña al occidente de Dolores (Tolima). Tesis, Universidad Nacional de Colombia, Bogotá, Colombia.

Ibáñez-Mejía, M.; Ruiz, J.; Valencia, V.A.; Cardona, A.; Gehrels, G.E.; Mora, A.R. (2011). The
Putumayo Orogen of Amazonia and its implications for Rodinia reconstructions: New U$\mathrm{Pb}$ geochronological insights into the Proterozoic tectonic evolution of northwestern South America. Precambrian Research, 191(1-2), 58-77. https:// doi.org/10.1016/j.precamres.2011.09.005

Ibáñez-Mejía, M.; Pullen, A.; Arenstein, J.; Gehrels, G.; Valley, J.; Ducea, M.; Mora, A.; Pecha, M.; Ruiz, J. (2015). Unraveling crustal growth and reworking processes in complex zircons from orogenic lower-crust: The Proterozoic Putumayo Orogen of Amazonia. Precambrian Research, 267, 285-310. https://doi.org/10.1016/j. precamres.2015.06.014

Irvine, T.N.; Baragar, W.R.A. (1971). A guide to the chemical classification of the common volcanic rocks. Canadian Journal of Earth Sciences, 8(5), 523-548. https://doi.org/10.1139/e71-055

Janoušek, V.; Farrow, C.M.; Erban, V. (2006). Interpretation of whole-rock geochemical data in igneous geochemistry: introducing Geochemical Data Toolkit (GCDkit). Journal of Petrology, 47(6), 1255-1259. https://doi.org/10.1093/ petrology/egl013

Jaramillo, L.; Escovar, R. (1980). Cinturones de pórfidos cupríferos en las cordilleras colombianas. Simposio sobre Metalogénesis en Latinoamérica. México D.F.

Jiménez-Mejía, D.M.; Juliani, C.; Cordani, U.G. (2006). P-T-t conditions of high-grade metamorphic rocks of the Garzon Massif, Andean basement, SE Colombia. Journal of South American Earth Science, 21(4), 322-336. https://doi.org/10.1016/j. jsames.2006.07.001

Kroonenberg, S.B. (1982). A Grenvillian granulite belt in the Colombian Andes and its relation to the Guiana Shield. Geologie en Mijnbouw, 61(4), 325-333.

Kroonenberg, S.; Diederix, H. (1982). Geology of South-Central Huila, Uppermost Magdalena Valley, Colombia. A preliminary note. Guide Book 21 Annual Field Trip, Colombia Society of Petroleum Geologists and Geophysicists, 39 p. Bogotá. 
Kroonenberg, S.B. (2019). The Proterozoic Basement of the Western Guiana Shield and the Northern Andes. In: F. Cediel; R.P. Shaw (eds.). Geology and Tectonics of Northwestern South America (pp. 115-192). Springer, Cham. https://doi. org/10.1007/978-3-319-76132-9_3

Leal-Mejía, H. (2011). Phanerozoic gold metallogeny in the Colombian Andes: A tectono-magmatic approach. PhD Thesis, Universitat de Barcelona, Barcelona, Spain.

Leal-Mejía, H.; Shaw, R.P.; Melgarejo, J.C. (2019). Spatial-Temporal Migration of Granitoid Magmatism and the Phanerozoic TectonoMagmatic Evolution of the Colombian Andes. In: F. Cediel; R.P. Shaw (eds.). Geology and Tectonics of Northwestern South America (pp. 253-410). Springer, Cham. https://doi.org/10.1007/978-3319-76132-9_5

Le Maitre, R.W.; Streckeisen, A.; Zanettin, B.; Le Bas, M.J.; Bonin, B.; Bateman, P.; Bellieni, G.; Dudek, A.; Efremova, S.; Keller, J.; Lameyre, J.; Sabine, P.A.; Schmid, R.; Sorensen, H.; Woolley A.R. (2002). Igneous Rocks: A Classification and Glossary of Terms. Recommendations of the International Union of Geological Sciences. Subcommission of the Systematics of Igneous Rocks. (2nd ed.). Cambridge University Press.

Loucks, R.R.; Fiorentini, M.L.; Henríquez, G. (2020). New magmatic oxybarometer using trace elements in zircon. Journal of Petrology. https:// doi.org/10.1093/petrology/egaa034

Lu, Y.J.; Loucks, R.R.; Fiorentini, M.L.; McCuaig, T.C.; Evans, N.J.; Yang, Z.M.; Hou, Z.Q.; Kirkland, C.L.; Parra-Avila, L.A.; Kobussen, A. (2016). Zircon compositions as a pathfinder for porphyry $\mathrm{Cu} \pm \mathrm{Mo} \pm$ Au deposits. In: J. Richards (ed.). Tectonics and Metallogeny of the Tethyan Orogenic Belt (pp. 329-347). Vol. 19. Society of Economic Geologists.

Lu, Y.J.; Smithies, R.H.; Wingate, M.T.D.; Evans, N.J.; Morris, P.A.; Champion, D.C.; McCuaig, T.C. (2018). Zircon composition as a fertility indicator of Archean granites. Geological Survey of Western Australia, 2, 18-23.

Ludwig, K.R. (2012). User's Manual for Isoplot 3.75-4.15. A geochronological toolkit Microsoft
Excel. Berkeley Geochronology Center, Special Publication, no. 5, 75p.

Mantilla-Figueroa, L.C.; García-Ramírez, C.A.; Valencia, V. (2016). Propuesta de escisión de la denominada 'Formación Silgará' (Macizo de Santander, Colombia), a partir de edades U-Pb en zircones detríticos. Boletín de Geología, 38(1), 33-50. https://doi.org/10.18273/revbol.v38n12016002

Maze, W.B.; Hargraves, R.B. (1984). Paleomagnetic results from the Jurassic La Quinta Formation in the Perijá Range, Venezuela, and their tectonic significance. In: W.E. Bonini; R.B. Hargraves; R. Shagam (eds.). The Caribbean-South American Plate Boundary and Regional Tectonics (pp. 287293). Vol. 162. Geological Society of America. https://doi.org/10.1130/MEM162-p287

McCourt, W.J.; Aspden, J.A.; Brook, M. (1984). New geological and geochronological data from the Colombian Andes: continental growth by multiple accretion. Journal of the Geological Society, 141(5), 831-845. https://doi.org/10.1144/ gsjgs.141.5.0831

Mesz, L. (2008). Caracterizacão tectono-magmática do norte da Cordilheira Centralda Colômbia, Batólito de Norosí, Região de San Lucas. Monografía de trabalho deformatura, Universidade de São Paulo, Brasil.

Meschede, M.; Frisch, W. (1998). A plate-tectonic model for the Mesozoic and Early Cenozoic history of the Caribbean plate. Tectonophysics, 296(3-4), 269-291. https://doi.org/10.1016/ S0040-1951(98)00157-7

Middlemost, E.A.K. (1994). Naming materials in the magma/igneous rock system. EarthScience Reviews, 37(3-4), 215-224. https://doi. org/10.1016/0012-8252(94)90029-9

Mojica, J. (1980). Observaciones acerca del estado actual del conocimiento de la Formación Payandé (Triásico Superior), Valle Superior del Río Magdalena, Colombia. Geología Colombiana, 11, 67-88.

Mojica, J.; Villarroel, C.; Cuerda, A.; Alfaro, M. (1988). La fauna de graptolites de la Formación El Hígado (Llanvirniano - Llandeiliano), Serranía 
de Las Minas, Valle Superior del Magdalena, Colombia. V Congreso Geológico Chileno, Santiago de Chile, Chile.

Nakamura, N. (1974). Determination of REE, Ba, $\mathrm{Fe}, \mathrm{Mg}, \mathrm{Na}$ and $\mathrm{K}$ in carbonaceous and ordinary chondrites. Geochimica et Cosmochimica Acta, 38(5), 757-775. https://doi.org/10.1016/00167037(74)90149-5

Nova, G.; Bayona, G.; Silva, J.; Cardona, A.; Rapalini, A.; Montaño, P.; Eisenhauer, A.; Dussan, K.; Valencia, V.; Ramírez, V.; Montes, C. (2018). Jurassic break-up of the Peri-Gondwanan margin in northern Colombia: Basin formation and implications for terrane transfer. Journal of South American Earth Sciences, 89, 92-117. https://doi. org/10.1016/j.jsames.2018.11.014

Núñez, A. (1978). Petrogénesis del Batolito de Ibagué. II Congreso Colombiano de Geología. Bogotá, Colombia.

Núñez, A.; Mosquera, D.; Vesga, C.J. (1984a). Reseña explicativa del mapa geológico preliminar plancha 263 Ortega. Escala 1:100.000. INGEOMINAS. Bogotá.

Núñez, A.; Mosquera, D.; Vesga, C. (1984b). Geología de la plancha 263 Ortega. Escala 1:100.000. INGEOMINAS, Bogotá.

Núñez, A.; Bocanegra, A.; Gómez, J. (1996). Los plutones Jurásicos del Valle Superior del Magdalena (Colombia). VII Congreso Colombiano de Geología. Bogotá, Colombia.

Ordóñez-Carmona, O.; Pimentel, M.M.; De Moraes, R. (2002). Granulitas de los Mangos, un fragmento grenvilliano en la parte oriental de la Sierra Nevada de Santa Marta. Revista de la Academia Colombiana de Ciencias Exactas, Físicas y Naturales, 26(99), 169-179.

Ordóñez-Carmona, O.; Frantz, J.C.; Chemale, F.; Londoño, C. (2009). Serranía de San Lucas: mineralizaciones auríferas, intrusiones de 1500 Ma, metamorfismo Grenville y magmatismo Jurásico. XII Congreso Colombiano de Geología. Paipa, Colombia.

Otamendi, J.E.; Ducea, M.; Cristofolini, E.A.; Tibaldi, A.M.; Camilletti, G.C.; Bergantz, G.W. (2017).
$\mathrm{U}-\mathrm{Pb}$ ages and $\mathrm{Hf}$ isotope compositions of zircons in plutonic rocks from the central Famatinian arc, Argentina. Journal of South American Earth Sciences, 76, 412-426. https://doi.org/10.1016/j. jsames.2017.04.005

Paton, C.; Woodhead, J.D.; Hellstrom, J.C.; Hergt, J.M.; Greig, A.; Maas, R. (2010). Improved laser ablation U-Pbzircongeochronology through robust downhole fractionation correction. Geochemistry, Geophysics, Geosystems, 11(3). https://doi. org/10.1029/2009GC002618

Pearce, J.A. (1996). A user's guide to basalt discrimination diagrams. In: D.A. Wyman (ed.). Trace Element Geochemistry of Volcanic Rocks: Applications for Massive Sulphide Exploration (pp. 79-113). Geological Association of Canada.

Pearce, J.A. (2008). Geochemical fingerprinting of oceanic basalts with applications to ophiolite classification and the search for Archean oceanic crust. Lithos, 100(1-4), 14-48. https://doi. org/10.1016/j.lithos.2007.06.016

Petrus, J.A.; Kamber, B.S. (2012). VizualAge: A novel approach to laser ablation ICP-MS U-Pb geochronology data reduction. Geostandards and Geoanalytical Research, 36(3), 247-270. https:// doi.org/10.1111/j.1751-908X.2012.00158.x

Pindell, J.; Dewey, J. (1982). Permo-Triassic reconstruction of Western Pangea and the evolution of the Gulf of Mexico-Caribbean region. Tectonics, 1(2), 179-211. https://doi.org/10.1029/ TC001i002p00179

Piraquive, A. (2017). Structural Framework, deformation and exhumation of the Santa Marta Schists: accretion and deformational history of a Caribbean Terrane at the north of the Sierra Nevada de Santa Marta. PhD. Thesis, Universidad Nacional de Colombia - Université Grenoble Alpes.

Priem, H.N.; Andriessen, P.; Boelrijk, N.A.; De Boorder, H.; Hebeda, E.; Huguett, A.; Verdurmen, E.; Verschure, R. (1982). Geochronology of the Precambrian in the Amazonas region of southeastern Colombia (western Guiana Shield). Geologie en Mijnbouw, 61, 229-242. 
Profeta, L.; Ducea, M.N.; Chapman, J.B.; Paterson, S.R.; Gonzales, S.M.H.; Kirsch, M.; Petrescu, L.; DeCelles, P.G. (2015). Quantifying crustal thickness over time in magmatic arcs. Scientific Reports, 5. https://doi.org/10.1038/srep17786

Quiceno-Colorado, J.; Osorio-Ocampo, S.; VallejoHincapié, F.; Salazar-Ríos, A.; Ossa-Meza, C.A.; Giraldo-Alzate, L.; Romero-Arboleda, L. (2016). Petrografía y geoquímica del Stock de Payandé y su posible relación con el magmatismo Jurásico al sur de Colombia. Boletín de Geología, 38(2), 39-53. https://doi.org/10.18273/revbol.v38n22016002

Quandt, D.; Trumbull, R.; Altenberger, U.; Cardona A.; Romer, R.; Bayona, G.; Ducea, M.; Valencia, V.; Vásquez, M.; Cortes, E.; Guzman, G. (2018). The geochemistry and geochronology of Early Jurassic igneous rocks from the Sierra Nevada de Santa Marta, NW Colombia, and tectono-magmatic implications. Journal of South American Earth Sciences, 86, 216-230. https://doi.org/10.1016/j. jsames.2018.06.019

Radelli, L. (1960). El basamento cristalino de la Península de La Guajira. Boletín Geológico, 8(13), 5-32.

Radelli, L. (1962). Las dos granitizaciones de la Península de La Guajira (Norte de Colombia). Geología Colombiana, 1, 5-20.

Ramos, V.A. (2008). The basement of the Central Andes: the Arequipa and related terranes. Annual Review of Earth and Planetary Sciences, 36, 289-324. https://doi.org/10.1146/annurev. earth.36.031207.124304

Restrepo, J.J.; Toussaint, J.F. (1989). Terrenos alóctonos en los Andes Colombianos: Explicación de algunas paradojas geológicas. $V$ Congreso Colombiano de Geología, Bucaramanga, Colombia.

Restrepo, P. (1995). Late Precambrian to Early Mesozoic tectonic evolution of the Colombian Andes based on new geochronological, geochemical and isotopic data. PhD Thesis, The University of Arizona, USA.

Restrepo, J.J.; Ordóñez-Carmona, O.; Martens, U.; Correa, A.M. (2009). Terrenos, complejos y provincias en la Cordillera Central Colombiana. Ingeniería, Investigación y Desarrollo, 9(2), 4956.

Restrepo, J.J.; Ordóñez-Carmona, O.; Armstrong, R.; Pimentel, M. (2011). Triassic metamorphism in the northern part of the Tahamí Terrane of the central cordillera of Colombia. Journal of South American Earth Sciences, 32(4), 497-507. https:// doi.org/10.1016/j.jsames.2011.04.009

Restrepo, J.J.; Toussaint, J.F. (2020). Tectonostratigraphic terranes in Colombia: An update. First part: Continental terranes. In: J. Gómez; D. Mateus-Zabala (eds.). The Geology of Colombia (pp. 45-95). Volume 1, Chapter 3. Servicio Geológico Colombiano. https://doi. org/10.32685/pub.esp.35.2019.03

Restrepo-Pace, P.A.; Ruiz, J.; Gehrels, G.; Cosca, M. (1997). Geochronology and $\mathrm{Nd}$ isotopic data of Grenville-age rocks in the Colombian Andes: new constraints for Late Proterozoic-Early Paleozoic paleocontinental reconstructions of the Americas. Earth and Planetary Science Letters, 150(34), 427-441. https://doi.org/10.1016/S0012821X(97)00091-5

Restrepo-Pace, P.; Cediel, F. (2019). Proterozoic basement, Paleozoic tectonics of NW South America, and implications for Paleocontinental reconstruction of the Americas. In: F. Cediel; R.P. Shawn (eds.). Geology and tectonics of Northwestern South America (pp. 97-112). Springer, Cham. https://doi.org/10.1007/978-3319-76132-9_2

Ríos-Blandón P.A. (2016). Petrografía y Geoquímica de la Granodiorita de Ipapure y su relación con las rocas encajantes en la Alta Guajira - Colombia. Tesis de Maestría, Universidad Nacional de Colombia, Bogotá, Colombia.

Rodríguez, G. (1995a). Petrografía y microtexturas del Grupo Garzón y el Granito de Anatexis de El Recreo, Macizo de Garzón, Cordillera OrientalColombia. Revista Ingeominas, 5, 17-36.

Rodríguez, G. (1995b). Petrografía del Macizo de La Plata - Departamento del Huila. Revista Ingeominas, 5, 5-16. 
Rodríguez, G.; Fuquen, J.A. (1989). Geología y prospección geoquímica de la Plancha 302-Aipe (Huila), Colombia. INGEOMINAS, Ibagué.

Rodríguez, G.; Ferreira, P.; Velandia, F.; Núñez, A. (1998). Geología de la Plancha 366 Garzón. Escala 1:100.000. INGEOMINAS. Bogotá.

Rodríguez, G.; Londoño, A.C. (2002). Memoria explicativa del Mapa Geológico del Departamento de la Guajira. Geología, Recursos Minerales y Amenazas Potenciales. Escala 1:250.000. Versión 2. INGEOMINAS, Medellín.

Rodríguez, G.; Zapata, G.; Velásquez, M.E.; Cossio, U.; Londoño, A.C. (2003). Geología de las planchas 367 Gigante, 368 San Vicente del Caguán, 389 Timaná, 390 Puerto Rico, 391 Lusitania (parte noroccidental) y 414 El Doncello. INGEOMINAS, Memoria explicativa, escala 1:100.000. Bogotá.

Rodríguez, G.; Arango, M.I.; Zapata, G.; Bermúdez, J.G. (2014). Petrografía y geoquímica del Neis de Nechí. Boletín de Geología, 36(1), 71-84.

Rodríguez, G.; Arango, M.I.; Zapata, G.; Bermúdez, J.G. (2015a). Características petrográficas, geoquímicas y edad U-Pb de los plutones Jurásicos del Valle Superior del Magdalena. XV Congreso Colombiano de Geología. Bucaramanga, Colombia.

Rodríguez, G.; Arango, M.I.; Bermúdez J.G.; Zapata G. (2015b). Catálogo de Unidades Litoestratigráficas de Colombia: Cuarzomonzonita de Los Naranjos, Cordillera Central Huila-Tolima. Servicio Geológico Colombiano, Bogotá.

Rodríguez, G.;Arango, M.I.; Zapata, G.; Bermúdez, J.G. (2015c). Catálogo de Unidades Litoestratigráficas de Colombia: Cuarzomonzodiorita de El Astillero, Serranía de las Minas, Huila. Servicio Geológico Colombiano, Bogotá.

Rodríguez, G.; Zapata, G.; Arango, M.I.; Bermúdez, J.G. (2015d). Catálogo de unidades Litoestratigráficas de Colombia: Monzogranito de Algeciras. Servicio Geológico Colombiano, Bogotá.

Rodríguez, G.; Arango, M.I.; Bermúdez, J.G.; Zapata, G. (2015e). Catálogo de Unidades
Litoestratigráficas de Colombia: Granito de Garzón, Cordillera Oriental, Departamento Huila. Servicio Geológico Colombiano, Bogotá.

Rodríguez, G.; Arango, M.I.; Zapata, G.; Bermúdez, J.G. (2015f). Caracterización Magmática del Jurásico del Valle Superior del Magdalena y Cuenca Putumayo. Servicio Geológico Colombiano, Bogotá.

Rodríguez, G.; Zapata, G.; Arango, M.I.; Bermúdez, J.G. (2017a). Caracterización petrográfica, geoquímica y geocronología de rocas granitoides Pérmicas al occidente de La Plata y Pacarní Huila, Valle Superior del Magdalena - Colombia. Boletín de Geología, 39(1), 41-68. https://doi. org/10.18273/revbol.v39n1-2017002

Rodríguez, G.; Obando, G.; Correa-Martínez, A.M.; Zapata, G.; Correa, T.; Obando, M.; Rincón, A.; Zapata, J.P. (2017b). Redefinición del bloque norte del Batolito de Ibagué con base en nuevos datos de petrografía, litogeoquímica y geocronología U-Pb. XVI Congreso Colombiano de Geología, Santa Marta, Colombia.

Rodríguez, G. (2018). Caracterización petrográfica, química y edad Ar-Ar de cuerpos porfídicos intrusivos en la formación Saldaña. Boletín Geológico, 44, 5-23. https://doi. org/10.32685/0120-1425/boletingeo.44.2018.5

Rodríguez, G.; Arango, M.I.; Zapata, G.; Bermúdez, J.G. (2018). Petrotectonic characteristics, geochemistry, and $\mathrm{U}-\mathrm{Pb}$ geochronology of Jurassic plutons in the Upper Magdalena ValleyColombia: implications on the evolution of magmatic arcs in the NW Andes. Journal of South American Earth Sciences, 81, 10-30. https://doi. org/10.1016/j.jsames.2017.10.012

Rodríguez, G.; Correa-Martínez, A.M.; ZapataVillada, J.P.; Obando-Erazo, G. (2019a). Fragments of a Permian arc on the western margin of the Neoproterozoic basement of Colombia. In: J. Gómez; D. Mateus-Zabala (eds.). The Geology of Colombia (pp. 293-335). Volume 1, Chapter 10. Servicio Geológico Colombiano. https://doi. org/10.32685/pub.esp.35.2019.10

Rodríguez, G.; Zapata-Villada, J.P., Correa-Martínez, A.M.; Ramírez, D.; Obando, G.; Muñoz, J.A.; Rayo, L.; Ureña, C.L. (2019b). Magmatismo 
Jurásico de la Sierra Nevada de Santa Marta SNSM. Servicio Geológico Colombiano, Bogotá.

Rodríguez, G.; Correa-Martínez, A.M.; ZapataGarcía, G.; Arango-Mejía, M.I.; ObandoErazo, G.; Zapata-Villada, J.P.; Bermúdez, J.G. (2020). Diverse Jurassic magmatic Arcs of the Colombian Andes: Constraints from petrography, geochronology and geochemistry. In: J. Gómez; D. Mateus-Zabala (eds). The Geology of Colombia (pp. 77-99). Volume 2, Chapter 4. Servicio Geológico Colombiano. https://doi.org/10.32685/ pub.esp.36.2019.04

Rollins, J. (1965). Stratigraphy and structure of the Goajira Peninsula, northwestern Venezuela and northeastern Colombia. University of Nebraska.

Ross, M.I.; Scotese, C.R. (1988). A hierarchical tectonic model of the Gulf of Mexico and Caribbean region. Tectonophysics, 155(1-4), 139-168. https://doi.org/10.1016/0040-1951(88)90263-6

Royero, J.M. (1996). Geología de la Plancha 65, Tamalameque (Departamentos del Cesar y Bolívar). Memoria Explicativa. INGEOMINAS. Bucaramanga.

Schoene, B.; Samperton, K.M.; Eddy, M.P.; Keller, G.; Adatte, T.; Bowring, S.A.; Khadri, S.F.R.; Gertsch, B. (2015). U-Pb geochronology of the Deccan Traps and relation to the end-Cretaceous mass extinction. Science, 347(6218), 182-184. https://doi.org/10.1126/science.aaa0118

Siégel, C.; Bryan, S.E.; Allen, C.M.; Gust, D.A. (2018). Use and abuse of zircon-based thermometers: A critical review and a recommended approach to identify antecrystic zircons. Earth-Science Reviews, 176, 87-116. https://doi.org/10.1016/j. earscirev.2017.08.011

Sláma, J.; Košler, J.; Condon, D.; Crowley, J.; Gerdes, A.; Hanchar, J.; Horstwood, M.; Morris, G.; Nasdala, L.; Norberg, N.; Schaltegger, U.; Schoene, B.; Tubrett, M.; Whitehouse, M.J. (2008). Plešovice zircon - A new natural reference material for $\mathrm{U}-\mathrm{Pb}$ and $\mathrm{Hf}$ isotopic microanalysis. Chemical Geology, 249(1-2), 1-35. https://doi.org/10.1016/j.chemgeo.2007.11.005

Solari, L.; Gómez-Tuena, A.; Bernal, J.; PérezArvizu, O.; Tanner, M. (2010). U-Pb Zircon
Geochronology with an Integrated LA-ICP-MS Microanalytical Workstation: Achievements in Precision and Accuracy. Geostandards and Geoanalytical Research, 34(1), 5-18. https://doi. org/10.1111/j.1751-908X.2009.00027.x

Spikings, R.; Cochrane, R.; Villagomez, D.; Van der Lelij, R.; Vallejo, C.; Winkler, W.; Beate, B. (2015). The geological history of northwestern South America: from Pangaea to the early collision of the Caribbean Large Igneous Province (290-75 Ma). Gondwana Research, 27(1), 95-139. https:// doi.org/10.1016/j.gr.2014.06.004

Stacey, J.S.; Kramers, J.D. (1975). Approximation of terrestrial lead isotope evolution by a two-stage model. Earth and Planetary Science Letters, 26(2), 207-221. https://doi.org/10.1016/0012821X(75)90088-6

Stibane, F.; Forero, A. (1969). Los afloramientos del Paleozóico en la Jagua (Huila) y Río Nevado (Santander del Sur). Geología Colombiana, 6, 31-66.

Streckeisen, A. (1976). To each plutonic rock its proper name. Earth Science Reviews, 12(1), 1-33. https:// doi.org/10.1016/0012-8252(76)90052-0

Streckeisen, A. (1978). IUGS Subcommission on the Systematics of Igneous Rocks. Classification and nomenclature of volcanic rocks, lamprophyres, carbonatites and melilitic rocks; recommendation and suggestions. Neues Jahrbuch für Mineralogie, Abhandlungen, 134, 1-14.

Sun, S.; McDonough, W. (1989). Chemical and isotopic systematics of oceanic basalts: implications for mantle composition and processes. Geological Society, London, Special Publications, 42, 313-345. https://doi.org/10.1144/GSL. SP.1989.042.01.19

Tassinari, C.C.G. (1981). Evolução geotectônica da província Rio Negro-Juruena na região amazônica. Dissertaçao de Mestrado, Universidade de São Paulo, São Paulo, Brasil. https://doi. org/10.11606/D.44.1981.tde-11062013-163626

Tassinari, C.C.G.; Macambira, M.J.B. (1999). Geochronological provinces of the Amazonian Craton. Episodes, 22(3), 174-182. https://doi. org/10.18814/epiiugs/1999/v22i3/004 
Tazzo-Rangel, M.D.; Weber, B.; González-Guzmán, R.; Valencia, V.; Frei, D.; Schaaf, P.; Solari, L. (2019). Multiple metamorphic events in the Palaeozoic Mérida Andes basement, Venezuela: insights from $\mathrm{U}-\mathrm{Pb}$ geochronology and $\mathrm{Hf}-$ $\mathrm{Nd}$ isotope systematics. International Geology Review, 61(13), 1557-1593. https://doi.org/10.10 80/00206814.2018.1522520

Toussaint, J.F. (1995). Evolución geológica de Colombia. Triásico - Jurásico. Universidad Nacional de Colombia.

Tschanz, C.M.; Jimeno, A.; Cruz, J. (1969a). Geology of the Sierra Nevada de Santa Marta (Colombia). Preliminary Report Ministerio de Minas y Energía. INGEOMINAS, Bogotá, Colombia.

Tschanz, C.M.; Jimeno, A.; Cruz, J. (1969b). Mapa geológico de reconocimiento de la Sierra Nevada de Santa Marta. 1 mapa escala 1: 200.000. INGEOMINAS y U.S. Geological Survey, Bogotá, Colombia.

Tschanz, C.M.; Marvin, R.; Cruz, J.; Mehnert, H.H.; Cebula G.T. (1974). Geologic evolution of the Sierra Nevada de Santa Marta Northeastern Colombia. GSA Bulletin, 85(2), 273-284. https:// doi.org/10.1130/0016-7606(1974)85<273:GEOT $\mathrm{SN}>2.0 . \mathrm{CO} ; 2$

Van der Lelij, R.; Spikings, R.; Mora, A. (2016). Thermochronology and tectonics of the Mérida Andes and the Santander Massif, NW South America. Lithos, 248-251, 220-239. https://doi. org/10.1016/j.lithos.2016.01.006

Velandia, F.; Ferreira, P.; Rodríguez, G.; Núñez, A. (1996). Memoria explicativa levantamiento geológico de la Plancha 366 - Garzón. INGEOMINAS. Bogotá.

Velandia, F.; Morales, C.; Caicedo, J.; Núñez, A. (1999). Geología de la Plancha 345 - Campoalegre. Escala 1:100.000. INGEOMINAS. Bogotá.

Velandia, F.; Ferreira, P.; Rodríguez, G.; Núñez, A. (2001a). Levantamiento geológico de la plancha 366 Garzón, Memoria explicativa. INGEOMINAS, Bogotá.
Velandia, F.; Núñez, A.; Marquínez, G. (2001b). Mapa geológico Departamento del Huila. Escala 1:300.000. Memoria explicativa. 153p. Bogotá.

Villagómez, D. (2010). Thermochronology, geochronology and geochemistry of the Western and Central cordilleras and Sierra Nevada de Santa Marta, Colombia: the tectonic evolution of NW South America. Ph.D. Thesis, University of Geneva, Geneva, Switzerland.

Villagómez, D.; Martens, U.; Pindell, J. (2015). Are Jurassic and some older blocks in the northern Andes in-situ or far-travelled?. Potential correlations and new geochronological data from Colombia and Ecuador. Simposio: Tectónica Jurásica en la Parte Noroccidental de Sur América y Bloques Adyacentes. Medellín, Colombia.

Villarroel, C.; Mojica, J. (1988). El Paleozoico Superior (Carbonífero-Pérmico) sedimentario de Colombia. Afloramientos conocidos y características generales. Geología Colombiana, 16, 81-87.

Villaseca, C.; Barbero, L.; Herreros. V. (1998). A reexamination of the typology of peraluminous granite types in intracontinental orogenic belts. Earth and Environmental Science Transactions of the Royal Society of Edinburgh, 89(2), 113-119. https://doi.org/10.1017/S0263593300007045

Ward, D.E.; Goldsmith, R.; Cruz, J.; Restrepo, H. (1973). Geología de los cuadrángulos H-12 Bucaramanga y H-13 Pamplona, departamento de Santander. Boletín Geológico, 21(1-3), 1-134.

Watson, E.B.; Wark, D.A.; Thomas, J.B. (2006). Crystallization thermometers for zircon and rutile. Contributions to Mineralogy and Petrology, 151(4), 413-433. https://doi.org/10.1007/s00410006-0068-5

Wiedenbeck, M.; Allé, P.; Corfu, F.; Griffin, W.L.; Meier, M.; Oberli, F.; von Quadt, A.; Roddick, J.C.; Spiegel, W. (1995). Three natural zircon standards for U-Th-Pb, Lu-Hf, trace element and REE analyses. Geostandards Newsletter, 19(1), 1-23. https://doi.org/10.1111/j.1751-908X.1995. tb00147.x 
Zapata, G.; Rodríguez, G.; Arango, M.I.; Bermúdez, J.G. (2015). Catálogo de Unidades Litoestratigráficas de Colombia: Cuarzomonzodiorita de Páez, Cordillera Central, Departamentos de Huila, Cauca y Tolima. Servicio Geológico Colombiano. 52 p, Bogotá.

Zapata, S.; Cardona, A.; Jaramillo, C.; Valencia, V.; Vervoort, J. (2016). U-Pb LA-ICP-MS geochronology and geochemistry of Jurassic volcanic and plutonic rocks from the Putumayo region (southern Colombia): tectonic setting and regional correlations. Boletín de Geología, 38(2), 21-38. https://doi.org/10.18273/revbol.v38n22016001

Zapata-García, G.; Rodríguez-García, G.; ArangoMejía, M.I. (2017). Petrografía, geoquímica y geocronología de rocas metamórficas aflorantes en San Francisco Putumayo y la vía PalermoSan Luis asociadas a los complejos La CochaRío Téllez y Aleluya. Boletín Ciencias de la Tierra, 41, 48-65. https://doi.org/10.15446/rbct. $\mathrm{n} 41.58630$

Zartman, R.E.; Doe, B.R. (1981). Plumbotectonicsthe model. Tectonophysics, 75(1-2), 135-162. https://doi.org/10.1016/0040-1951(81)90213-4

Zuluaga, C.; Ochoa, A.; Muñoz, C.; Guerrero, N.; Martínez, A.M.; Medina, P.; Pinilla, A.; Ríos, P.; Rodríguez, B.; Salazar, E.; Zapata, V. (2009). Memoria de las planchas 2, 3, 5, y 6 (con parte de las planchas 4, 10 y 10bis). Proyecto de investigación: cartografía e historia geológica de la Alta Guajira. Universidad Nacional de Colombia - INGEOMINAS, 563 p, Bogotá.

Zuluaga, C.; Pinilla, A.; Mann, P. (2015). Jurassic silicic volcanism and associated Continentalarc basin in Northwestern Colombia (Southern boundary of the Caribbean plate). In: C. Bartolini; P. Mann (eds.). Petroleum geology and potential of the Colombian Caribbean margin (pp. 137159). AAPG memoir 108.

Zuluaga, C.A.; Amaya, S.; Urueña, C.; Bernet, M. (2017). Migmatization and low-pressure overprinting metamorphism as record of two pre-Cretaceous tectonic episodes in the Santander Massif of the Andean basement in northern Colombia (NW South America). Lithos, 274-275, 123-146. https://doi.org/10.1016/j. lithos.2016.12.036

Zuluaga, C.; López, J. (2019). Ordovician Orogeny and Jurassic Low-Lying Orogen in the Santander Massif, Northern Andes (Colombia). In: F. Cediel; R.P. Shaw (eds.). Geology and Tectonics of Northwestern South America (pp. 195-250). Springer, Cham. https://doi.org/10.1007/978-3319-76132-9_4

Trabajo recibido: agosto 02 de 2019

Trabajo aceptado: julio 23 de 2020 